\title{
EPIDEMIOLOGY AND MECHANISMS RELATING DIET TO RISK OF COLORECTAL CANCER
}

\author{
SHEILA A. BINGHAM
}

Medical Research Council, Dunn Clinical Nutrition Centre, Cambridge CB2 2DH

\section{CONTENTS}

INTRODUCTION

GENETIC FACTORS AND DIET . . . . . . . . . . . . . 201

EPIDEMIOLOGY OF DIET AND COLORECTAL CANCER . . . . . 203

MAIN FACTORS (FAT, MEAT, STARCH, NON-STARCH POLYSACCHARIDES, VEGETABLES)

Cross-sectional comparisons . . . . . . . . . . . . . . . 203

Retrospective case-control studies . . . . . . . . . . . . . . . . 204

Cohort studies . . . . . . . . . . . . . . . . . 205

Studies in patients with adenomatous polyps. . . . . . . . . . . . 209

OTHER DIETARY FACTORS. . . . . . . . . . . . . 210

Calcium. . . . . . . . . . . . . . . . 210

Iron . . . . . . . . . . . . . . . . . . . 211

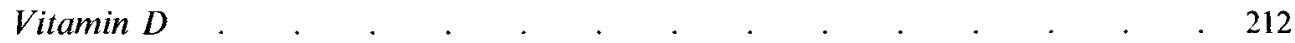

Vitamins $E$ and $C$. . . . . . . . . . . . . . . . . . 212

Folate . . . . . . . . . . . . . . . . 212

Alcohol . . . . . . . . . . . . . . . . . 213

Energy balance and exercise . . . . . . . . . . . . . . . . . . .

INTER VENTION STUDIES

DIET AND CHEMICALLY INDUCED CARCINOGENESIS . . . . $\quad 214$

NON-STARCH POLYSACCHARIDES, STARCH . . . . . . . . . 214

FAT, ENERGY .

n-3 AND n-6 FATTY ACIDS . . . . . . . . . . . . 215

PROTEIN AND MEAT . . . . . . . . . . . . . . . . . . 216

POTENTIAL MECHANISMS . . . . . . . . . . . . . . . . . . . 216

THE COLONIC FLORA AND FERMENTATION . . . . . . . . . . 216

Carbohydrate. . . . . . . . . . . . . . . . . . 216

Dilution, stool weight and transit time . . . . . . . . . . . . 217

Butyrate. . . . . . . . . . . . . . . 217

Fat, bile acids, $\mathrm{pH}$. . . . . . . . . . . . . . . . . . . . . . . . . 218

Diacylglycerol . . . . . . . . . . . . . . . . . 218

Calcium. . . . . . . . . . . . . . . . . . . . 219 
Fecapentaenes

Bacterial deconjugation .

Sulphite.

Nitrogen metabolism

Ammonia

$N$-nitroso compounds

Heterocyclic aromatic amines

n-3 and n-6 fatty acids .

Effects of diet on Phase I and II enzyme activity .

Nutrients

Vegetables

Folate

Flavonoids

SUMMARY AND CONCLUSIONS

\section{INTRODUCTION}

Colorectal cancer is the second most common cancer in Western societies, affecting up to $6 \%$ of men and women by the age of 75 . It ranks second after lung cancer in men, and breast cancer in women. Table 1 shows age standardized incidence rates for men and women for the major cancers in England and Wales. Incidence is increasing slightly, particularly in men, but mortality is decreasing owing to improvements in detection and treatment. Like most cancers, risks increase with age and Fig. 1 shows rates for colon and rectal cancer at different ages for men and women in England and Wales (Muir et al. 1987).

When age is taken into account, there remains at least a 15-fold range in age standardized incidence throughout the world. Countries with the highest risk include Australia, New Zealand, the USA and parts of Northern Europe, and those with the lowest risk include rural Africa, China and India (Parkin et al. 1992). In low risk countries, the majority of colorectal cancers are situated in the right side of the colon, whereas in high risk countries the majority of cancers are located in the lower bowel, near the rectosigmoid junction.

Both migrant studies and secular changes in incidence rates show that environmental factors are the main reason for the geographical differences in colorectal cancer incidence. Migrants from low risk areas rapidly adopt the incidence rates of a high risk population, for example Japanese migrants to Hawaii, Southern Europe migrants to Australia (McMichael et al. 1980; Haenszel et al. 1973). In Japan itself, there have been striking changes. Whereas rates were once low, age specific colorectal cancer incidence rates have increased markedly since 1960, and are approaching those recorded in Britain (Fig. 2). Death rates from large bowel cancer in younger (30-40-year-old) Japanese are falling, however (Boyle et al. 1993).

The strong evidence that the majority of large bowel cancers are attributable to environmental factors means that it is a potentially preventable disease. In addition, cancer is generally accepted to be a disease of genes, occurring as a result of mutations in or loss of genes in the large bowel epithelium, leading to malignant growth. In comparatively rare 
DIET AND COLORECTAL CANCER

Table 1. Age standardized rates per 100000 for major cancers excluding skin in men and women in England and Wales 1983-1987 (Parkin et al. 1992)

\begin{tabular}{lclc}
\hline \hline Site & Male & Site & Female \\
\hline Bronchus, lung & $65 \cdot 4$ & Breast & $56 \cdot 1$ \\
Colorectal & $30 \cdot 8$ & Colorectal & $22 \cdot 4$ \\
Prostate & $23 \cdot 1$ & Bronchus, lung & $20 \cdot 5$ \\
Bladder & $17 \cdot 7$ & Uterus & $19 \cdot 9$ \\
Stomach & $16 \cdot 9$ & Ovary & $11 \cdot 4$ \\
Pancreas & $7 \cdot 4$ & Stomach & $6 \cdot 8$ \\
Oesophagus & $6 \cdot 5$ & Bladder & $4 \cdot 9$ \\
Kidney & $5 \cdot 6$ & Pancreas & $4 \cdot 9$ \\
\hline
\end{tabular}

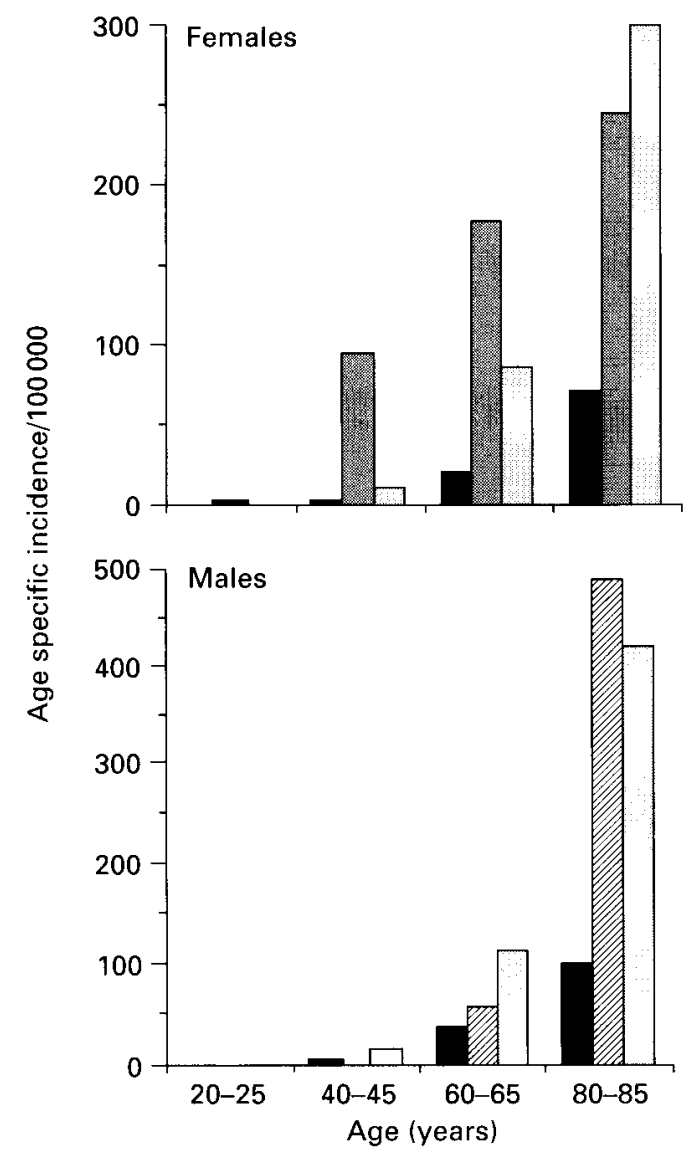

Fig. 1. Age specific incidence rates for different cancers ( $\mathbf{\square}$ ), pancreas; (团), breast; ( ( (). , large bowel; in England and Wales from ages 20 to 85 in 1983-1987 (Muir et al. 1987).

cases, these genetic defects are inherited, but the majority of large bowel cancers in societies where it is common are sporadic because affected patients have no known family history. The investigation of tumours from patients with inherited types of colorectal cancer has provided insight into the sporadic form of the disease because the same mutations occur in 


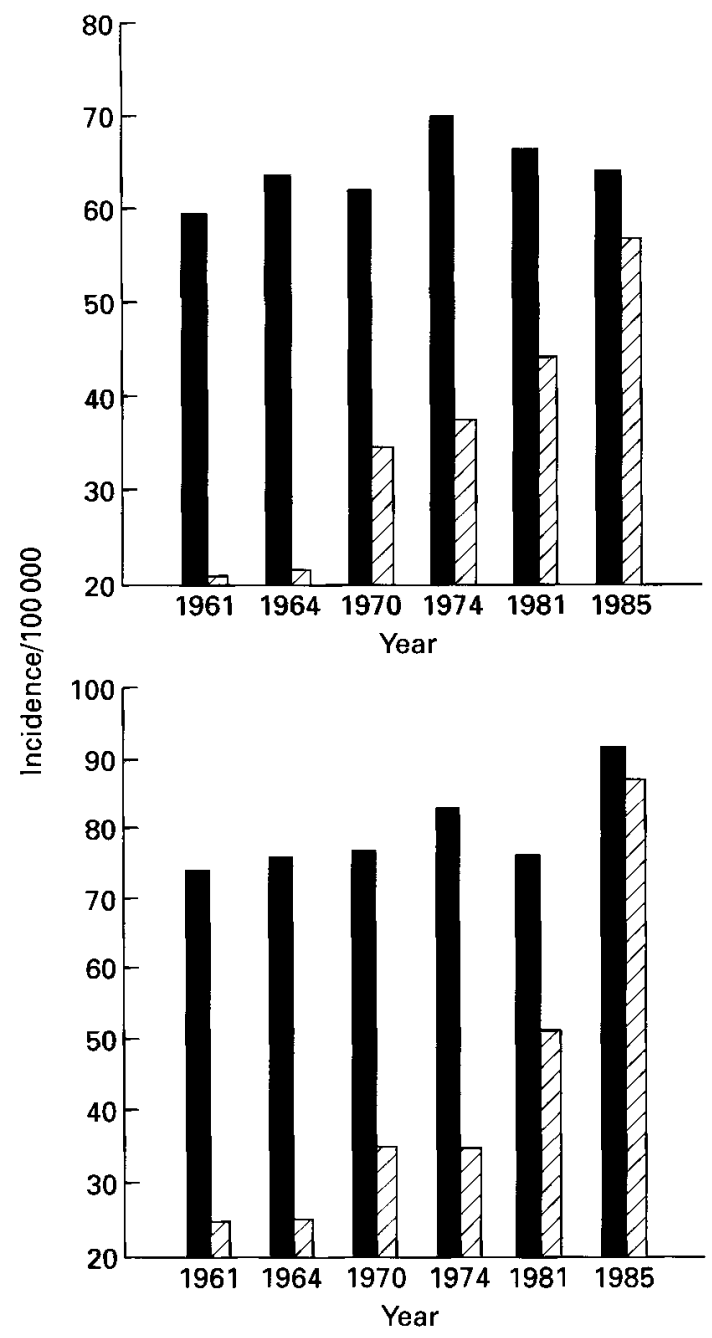

Fig. 2. 25 year secular trends in age specific colorectal cancer incidence rates in women and men aged 55-60 years in Japan (Miyagi registry) and in the UK (Birmingham registry). Solid columns UK, Hatched columns, Japan (Parkin et al. 1992 and preceding volumes Cancer Incidence in Five Continents, vols I-V, e.g. Muir et al. 1987).

both types to a significant extent (Bodmer et al. 1987; Solomon et al. 1987). This leads to the supposition that environmental factors are involved in somatic alterations in sporadic cancer. At present, the extent to which diet is capable of causing somatic alterations in genes known to be involved in the causation of cancer, or is able to prevent or mitigate these alterations, is an emerging area of research (see pp. 201-202).

For the time being, evidence linking diet with colorectal cancer is limited to epidemiological associations with support from experimental studies and plausible hypotheses. This review details the epidemiological evidence on pp. 203-214 and potential mechanisms in pp. 216-227. Overall conclusions linking the two are then summarized (pp. 227-228). Pp. 214-216 summarize the effect of diet found in animal models of colorectal cancer. 


\section{GENETIC FACTORS AND DIET}

The development of cancer is generally thought to have a number of stages - primarily initiation, promotion and progression. Until recently, diet was not implicated in initiation but high fat diets, for example, were shown to promote or increase the numbers of tumours initiated by large doses of carcinogens in animal models (see pp. 214-216). With the development of new techniques, genetic models for human cancer have been proposed, and those for colorectal cancer are the most advanced.

Benign tumours or polyps (adenomas) occurring in the wall of the large bowel are premalignant lesions, known to confer increased risks of malignant tumours developing at a later stage. The risk of cancer increases with the size and numbers of polyps (Lotfi et al. 1986; Schofield \& Jones, 1992). Vogelstein et al. (1988) were the first to demonstrate stepwise accumulation of chromosome deletions and mutations as disease progressed through adenomas to carcinoma. If diet does have a direct effect on somatic mutations, different dietary factors are likely to affect different stages of this sequence. Fig. 3 shows the original data on which present models are based. In these studies, few mutations or deletions were shown in small adenomas, but over $40 \%$ of larger adenomas and carcinomas had ras (see below) mutations, indicating that they occurred at an early stage. By the carcinoma stage, there were multiple deletions, $70 \%$ with deletions on chromosomes 18 and 17, later associated with loss of the p53 gene (see below). Fig. 4 is a later model, showing progression from normal epithelium through benign polyps to malignant tumours, with the progressive accumulation of these and other genetic mutations or chromosome deletions.

The first event is attributed to a mutation on chromosome 5, which is strongly associated with polyp development. The gene concerned (APC) is also a tumour suppressing gene, and was initially discovered in patients with a rare inherited syndrome known as familial adenomatous polyposis coli (Bodmer et al. 1987). Deletions on chromosome 5 also occur in sporadic tumours (Solomon et al. 1987).

Mutations of the ras gene, located on chromosome 12 and involved in the control of cellular proliferation and differentiation, occur in about half of colon cancers. As shown above, they occur less frequently in adenomas, indicating that ras mutation occurs before the conversion to malignant carcinoma. Particular types of mutations are most commonly involved (G-A transitions at the second $\mathrm{G}$ of a GG pair at codon 12 or 13 of $\mathrm{K}$ ras) and these are characteristic of alkylating agents such as $N$-nitroso compounds (NOC) (Bos, 1989). Faecal levels of NOC are elevated after a high meat diet (see p. 216).

Deletions on chromosomes 18 and 17 are common in colorectal carcinomas and are associated with loss of tumour suppressing genes. The DCC (deleted in colon cancer) gene is located on chromosome 18 , and the gene on chromosome 17 encodes for the nuclear phosphoprotein $p 53$, which controls a checkpoint in the cell cycle, is a trigger for programmed cell death (apoptosis) and is part of a pathway responsible for DNA damage repair (Friend, 1994). Mutant p53 has a prolonged half life and, as shown above, has been detected in $70 \%$ of colorectal carcinomas (Vogelstein et al. 1988). p53 mutations commonly occur in cancers of other organs, but the type of the mutations in the genes is specific to particular sites. p53 mutations in large bowel cancers for example are most commonly found at codons $175,248,273$ at $\mathrm{CpG}$ hotspots, with $\mathrm{G}: \mathrm{C}$ and $\mathrm{A}$ : $\mathrm{T}$ transitions found in $79 \%$ (Hollstein et al. 1991). Cytosine could be deaminated, leading to a transition to thymine, either spontaneously through oxidative damage, by relative deficiency of methyl groups or in the presence of nitrite (Harris, 1993). These latter factors could be affected by diet (see pp. 222-223, 226). Butyrate (see pp. 217-218) induces apoptosis in colonic cell lines. 


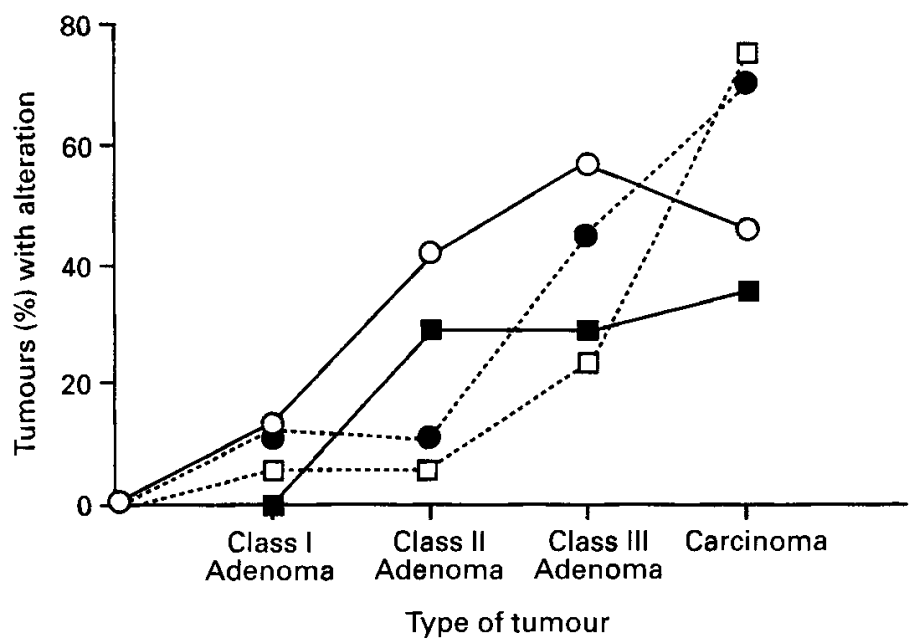

Fig. 3. Genetic alterations during colorectal tumour progression (O), ras mutation; ( $\square$ ), 5q allelic deletion; (O), 18q allelic deletion; $(\square), 17 p$ allelic deletion (reproduced with permission from Vogelstein et al. (1988).

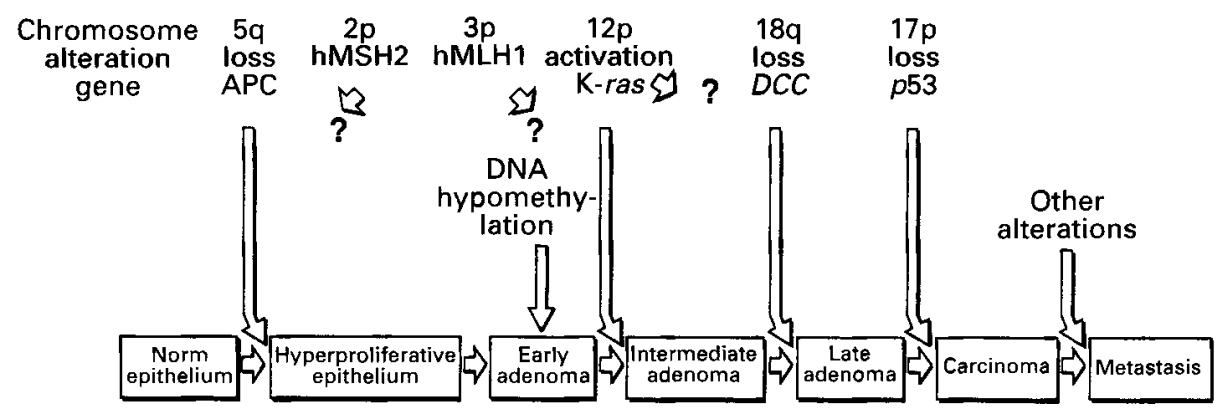

Fig. 4. Genetic model for colorectal cancer, adapted from Fearon \& Vogelstein (1990), showing possible interactions with diet.

In another inherited syndrome, the Lynch syndrome (also called Hereditary NonPolyposis Colorectal Cancer), in which polyps do not occur but affected individuals may develop cancer in other organs in addition to the bowel, another mutant gene has been found on chromosome 2 (Peltomäki et al. 1993). This familial colorectal cancer gene appears to be responsible for maintaining accurate DNA replication in many different locations in chromosomes. Mutation of this gene leads to multiple small changes, or microsatellite instability, that would induce greater susceptibility to colon (and other) cancers in patients with the Lynch syndrome. Microsatellite instability also occurs in another gene on chromosome 3 in hereditary non-polyposis colorectal cancer (Bronner et al. 1994). In rats one of the heterocyclic amines found in cooked meat is able to induce microsatellite instability (see pp. 223-224).

Particular genotypes have also been found to be at increased risk of colon cancer, for example those who are glutathione S-transferase competent or null (Strange et al. 1991) (see p. 225). Fig. 4 shows possible interactions between dietary factors and the genetic model of colorectal cancer. 


\title{
EPIDEMIOLOGY OF DIET AND COLORECTAL CANCER
}

\author{
MAIN FACTORS (FAT, MEAT, STARCH, NON-STARCH \\ POLYSACCHARIDES, VEGETABLES)
}

\section{Cross-sectional comparisons}

A number of comparisons between varying colorectal cancer rates worldwide and diet have been made. Higginson \& Oettle and Burkitt and coworkers were among the first to document differences in colorectal cancer incidence among different groups in South Africa, and to attribute the low rates in the Bantu to the fact that "in the Bantu a large amount of roughage is consumed and constipation in the Western sense is rare" (Higginson \& Oettle, 1960; Burkitt, 1969). In Japan, the secular trends in colorectal cancer incidence have been accompanied by increasing westernization of the diet, so that meat intakes have increased 9 -fold since 1950 and fat intakes 3-fold. Rice (and probably starch) consumption fell by one third, but there was little change in non-starch polysaccharide (NSP; dietary fibre) consumption over this time (Minowa et al. 1983; Kuratsune et al. 1986). However, owing to the low content of NSP in rice, Japanese intakes of NSP have never been high.

In the UK there was a decline in colorectal cancer rates during the 1940s and 1950s, which has been attributed to the $12 \mathrm{~g}$ per day wartime increase of NSP intakes (McMichael et al. 1979; Powles \& Williams, 1984).

Armstrong \& Doll (1975) attributed much of the international variation in large bowel cancer incidence between countries to dietary differences, especially meat and fat consumption. The relationship with meat is shown in Fig. 5. Other ecological studies of this type have found similar strong positive associations between fat and animal protein consumption and bowel cancer mortality (Drasar \& Irving, 1973; Howell, 1975; Thind, 1986). McKeown-Eyssen \& Bright-See (1985) correlated dietary fibre intakes in addition with colon cancer mortality rates in 38 countries. They reported higher estimates of dietary fibre intake in low colon cancer risk countries $(r=-0.66)$. However, because of the strong correlation with meat and fat ( $r=0.88$ and 0.74 respectively), the fibre correlations became non-significant when partial correlation analysis taking into account meat and fat was performed $(r=-0 \cdot 18,-0 \cdot 36)$.

Within the UK, where meat ( $150 \mathrm{~g}$ per day) and fat ( $100 \mathrm{~g}$ per day) intakes are high, partial correlation controlling for fat, beef and protein suggested that the protective associations with NSP were independently related to bowel cancer (Bingham et al. 1979, 1985). Significant inverse relations between bowel cancer and intakes of NSP and dietary fibre were also obtained from two studies of geographical areas at differing risk of colorectal cancer within Scandinavian populations, and in Germany (IARC, 1982; Boing et al. 1985).

When accurately measured, the amount of NSP found in diets worldwide is much less than the other major polysaccharide in food, starch. Information on starch intake is rarely reported in the literature, because most papers confine their reports to total carbohydrate estimates. Older food tables estimated carbohydrates 'by difference' and direct measurement of sugars and starches was not undertaken. In a recently published study of individual surveys of food consumption in 12 countries, starch consumption was assessed (Cassidy et al. 1994). A positive association with protein and fat $(r=0.60$ and 0.62 respectively) was corsirmed, and weak negative associations with NSP $(r=-0.23)$. There were, however, strong $(r=-0.70)$ inverse associations between colorectal cancer incidence and starch intake. These were maintained after partial correlation controlling for meat and fat consumption.

Cross-sectional examinations to date have therefore concentrated on relations with fat, 


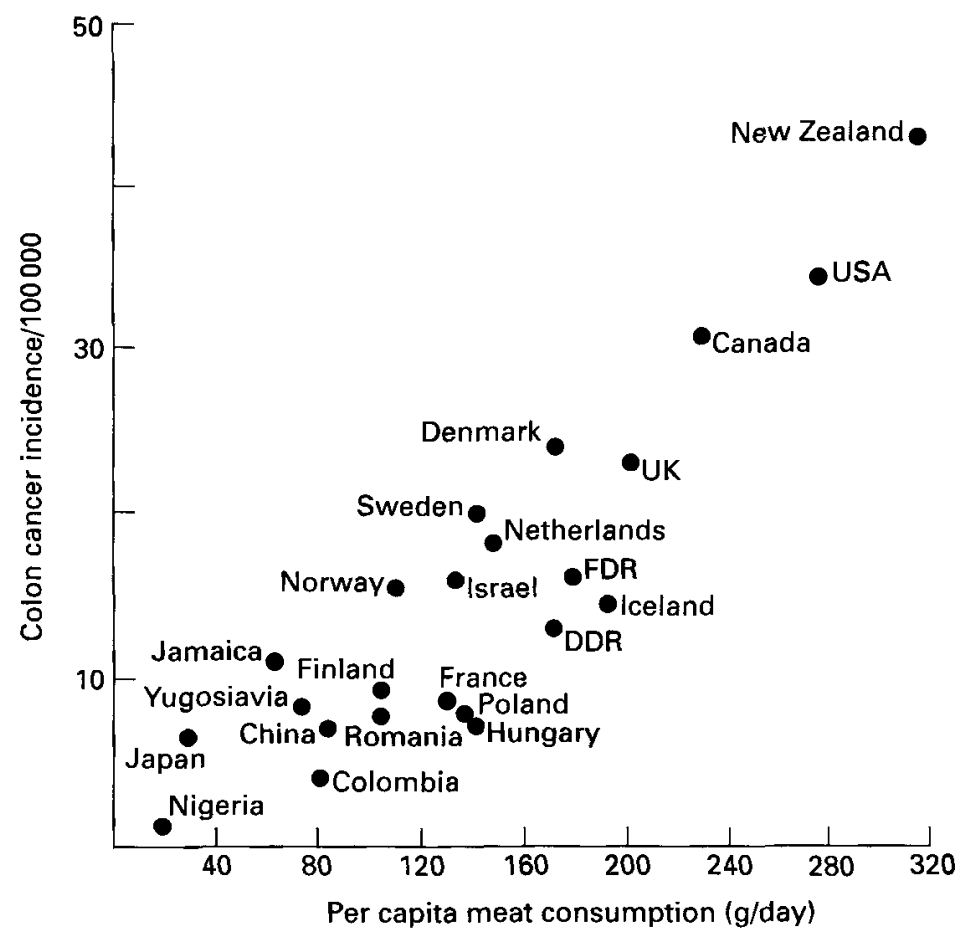

Fig. 5. The relationship between meat consumption and colorectal cancer in various countries, adapted from Armstrong \& Doll (1975).

meat and NSP (fibre). High meat and fat intakes seem to be prerequisites for high colorectal cancer incidence, and within these high risk populations increased levels of NSP are protective. Vegetarians are generally at lower risk (Johansson, 1990; Frentzel-Beyme \& Chang-Claude, 1994). Vegetables and starch also have strong protective associations against colorectal cancer. In the UK, regional differences in colorectal cancer mortality are strongly related to consumption of vegetables excluding potatoes $(r=-0.94)$ (Bingham $e t$ al. 1979).

\section{Retrospective case-control studies}

Analytic epidemiological studies offer major advantages over cross-sectional population studies because individual exposure to a dietary variable can be related to individual outcome. The most common type of study is the retrospective case-control, whereby patients with bowel cancer are studied after diagnosis and the results compared with those of controls who are healthy, or hospitalized for other conditions.

Reviews of some 30-35 existing case-control studies, conducted in widely varying circumstances and populations, including the USA, Japan, Canada, Australia, France and Belgium, have all concluded that the majority of studies of this sort indicate an increased risk of colorectal cancer in individuals who reported consuming more meat, protein and fat, and an increased risk for those reporting a lower consumption of fibre or fibre-containing foods (Bingham, 1990a, b; Trock et al. 1990; Margetts, 1994; Potter et al. 1994).

There is also a consistent inverse association with protection from vegetables. According to Potter et al. (1994), 23 out of 28 studies reporting results for vegetables showed a significant inverse association. In a meta-analysis of case-control studies, relative risk 
estimates for vegetables alone $(0 \cdot 48)$ were only slightly more convincing than those based on fibre intake (0.58) (Trock et al. 1990). Attributable population risk estimates from casecontrol studies suggest that $25-35 \%$ of colorectal cancers might be prevented by high intake of vegetables and fibre and that $15-25 \%$ could be attributed to a high fat intake (Tomatis et al. 1990). Measurement of starch consumption has only rarely been attempted in case-control studies; one study showed a significant reduction in risk with starch, and two others showed no effect (Tuyns et al. 1987; Slattery et al. 1988; Zaridze et al. 1993).

A major drawback of case-control studies is that the most common symptoms in large bowel disease are pain and altered bowel function (Cummings, $1981 \mathrm{a}$ ), which patients may attempt to ameliorate by a change in diet. An attempt to avoid this potential bias is made in case-control studies of diet by asking for details of past dietary habits. This procedure is difficult to validate with certainty, but circumstantial and other evidence suggests that recall of past diet is strongly influenced by present diet, since reports of past dietary consumption are more closely related to present consumption, and the discrepancy is greater the longer the period of recall (Friedenreich et al. 1992). Recall bias has not been assessed in case-control studies of large bowel cancer, but relative risks for breast cancer were higher in relation to high fat intake in two case-control assessments compared with those found in the same individuals assessed prospectively (Friedenreich et al. 1991; Giovannucci et al. 1993b).

\section{Cohort studies}

Cohort studies are designed to eliminate bias arising from consequence rather than cause of disease, but need to be large to accumulate sufficient power. Results of studies set up several years ago are now beginning to appear in the literature, but the need for accuracy in dietary assessment has only recently been recognized, hence very crude assessments of dietary intake, mainly based on short lists of foods (food frequency questionnaires) were used in most of these. These assessments would have been associated with a substantial degree of measurement error not amenable to correction. The major drawback with these types of methods is that hypotheses are likely to change over the course of a 10-year prospective study and the list of foods devised for a food or nutrient concerned with one hypothesis (for example fat consumption) is unlikely to be suitable for another, such as NSP or vegetables. There is currently much interest in minor constituents of the diet (see below) and factors such as cooking practices may become increasingly important; prospective studies that include detailed estimates of food consumption (or biomarkers of intake) are more likely to be able to investigate any relationship between these factors and cancer risk. Equally, risks from diet are more likely to be measurable in cohorts of individuals with widely differing dietary habits, for example in the European Prospective Investigation of Cancer; this is a cohort of 400000 individuals in nine European countries, from northern countries such as Sweden and the UK to Mediterranean countries such as Greece and Spain. Information being collected from all participants includes not only estimates of diet but also the collection of biological specimens which will be used to link diet and cancer registrations with intermediate markers of risk such as hormonal status, DNA adducts, biomarkers of diet and genotypic risk factors.

No biomarker of colon cancer risk is currently available, but the usefulness of biomarkers in characterizing individual risk is illustrated in a follow-up study of markers of aflatoxin exposure in relation to liver cancer. The range of aflatoxin contamination of foods is very great, so that use of food tables of average levels of contamination is unlikely to pick up individual exposure. Relative risks of cancer from aflatoxin consumption were only 0.9 and insignificant ( $95 \%$ confidence intervals (CI) $0.4-1.9)$ for individuals classified as having had high dietary exposure, as assessed by an interview on the frequency of con- 
Table 2. Trends in risk of large bowel cancer in prospective studies by quantile of fat and meat

\begin{tabular}{|c|c|c|c|}
\hline Total number & $\begin{array}{l}\text { Significant positive } \\
\text { association }\end{array}$ & $\begin{array}{l}\text { Significant inverse } \\
\text { association }\end{array}$ & Effects not significant \\
\hline \multicolumn{4}{|l|}{ Fat } \\
\hline \multirow[t]{5}{*}{8} & Morgan et al. 1988 & Stemmermann et al. 1984 & Garland et al. 1985 \\
\hline & Willett et al. 1990 & & Thun et al. 1992 \\
\hline & & & Bostick et al. 1994 \\
\hline & & & Giovannucci et al. 1994 \\
\hline & & & Goldbohm et al. 1994 \\
\hline \multicolumn{4}{|l|}{ Total meat } \\
\hline 3 & & Hirayama, 1981 & Phillips \& Snowdon, 1993 \\
\hline & & & Goldbohm et al. 1994 \\
\hline \multicolumn{4}{|l|}{ White meat } \\
\hline 6 & & Willett et al. 1990 & Heilbrun et al. 1989 \\
\hline & & & Thun et al. 1992 \\
\hline & & & Bostick et al. 1994 \\
\hline & & & Goldbohm et al. 1994 \\
\hline & & & Giovannucci et al. 1994 \\
\hline \multicolumn{4}{|l|}{ Red meat } \\
\hline \multirow[t]{4}{*}{6} & Willett et al. 1990 & & Heilbrun et al. 1989 \\
\hline & Giovannucci et al. 1994 & & Thun et al. 1992 \\
\hline & & & Bostick et al. 1994 \\
\hline & & & Goldbohm et al. 1994 \\
\hline \multicolumn{4}{|l|}{ Processed meat } \\
\hline 4 & Willett et al. 1990 & & Bostick et al. 1994 \\
\hline & Goldbohm et al. 1994 & & Giovannucci et al. 1994 \\
\hline
\end{tabular}

sumption of 45 foods. However, aflatoxin exposure biomarkers in urine samples obtained from individuals in the cohort were able to detect substantial significant relative risks for liver cancer in the order of $6-10$. Relative risks were $59 \cdot 4(16 \cdot 6-212 \cdot 0)$ in individuals positive for urine biomarkers of both aflatoxin and hepatitis B (Quian et al. 1994). Unfortunately the accessibility of suitable samples for biomarker analysis is likely to be more difficult in colon cancer, owing to the need to sample either faecal matter or mucosal tissue.

Of the existing studies which have reported, total fat intake has been measured in eight prospective cohort studies of large bowel cancer (Stemmermann et al. 1984; Garland et al. 1985; Morgan et al. 1988; Willett et al. 1990; Thun et al. 1992; Bostick et al. 1994; Giovannucci et al. 1994; Goldbohm et al. 1994). In two (Morgan et al. 1988; Willett et al. 1990) there was a significant positive association between trends in fat consumption and large bowel cancer (Table 2). The majority of studies showed no significant effects, and one suggested a significantly lower risk with higher fat intake (Stemmermann et al. 1984). However, most studies in which relative risks have been reported suggest an elevation of relative risk for individuals at the upper ends of the distribution in fat consumption, although confidence intervals generally embrace 1.00 and relative risks are less than 2 (Fig. 6). Available evidence to date, therefore, is weakly supportive of an increased risk of bowel cancer with high fat diets, although results from more accurate ongoing prospective studies are awaited.

Various indices of meat consumption have been measured in eight prospective studies (Hirayama, 1981; Phillips \& Snowdon, 1985; Heilbrun et al. 1989; Willett et al. 1990; Thun et al. 1992; Bostick et al. 1994; Giovannucci et al. 1994; Goldbohm et al. 1994). Table 2 shows that few studies have reported risks from total meat consumption in colorectal 
Prospective studies

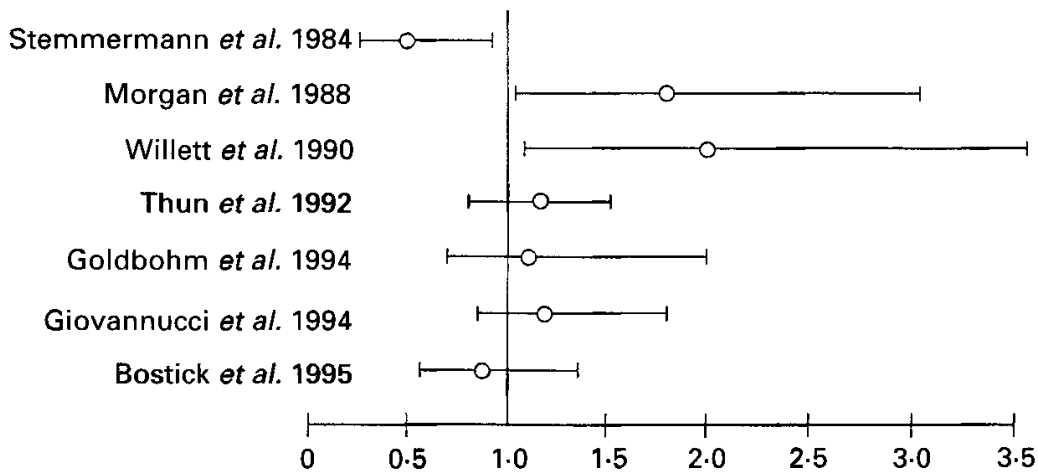

Fig. 6. Relative risks for colon cancer and $95 \%$ confidence intervals for the highest $v$. the lowest quartile of fat consumption in prospective studies.

Willett et al. 1990

Thun et al. 1992

Giovannucci et al. 1994

Bostick et al. 1994

Goldbohm et al. 1994

Willett et al. 1990

Giovannucci et al. 1994

Bostick et al. 1994

Goldbohm et al. 1994

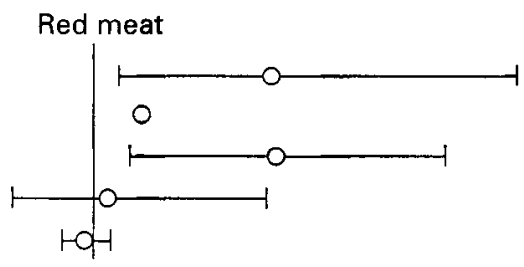

Willett et al. 1990

Thun et al. 1992

Giovannucci et al. 1994

Bostick et al. 1994

Goldbohm et al. 1994
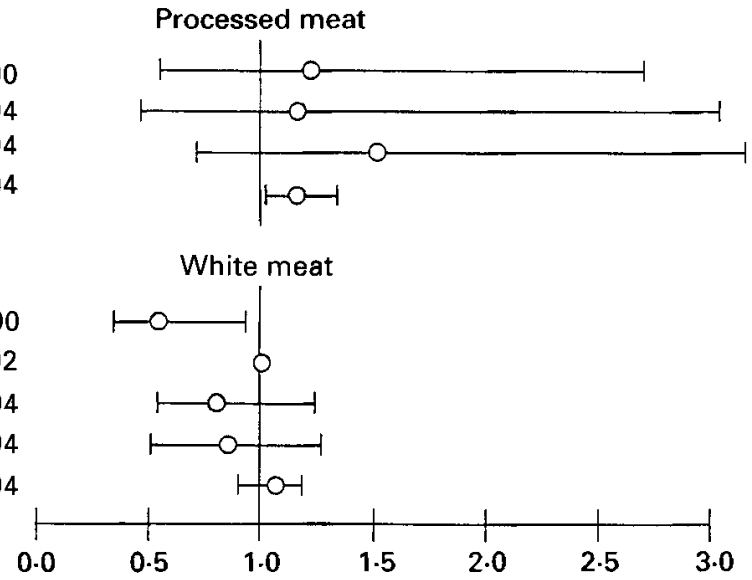

Fig. 7. Relative risks for colon cancer and $95 \%$ confidence intervals for the highest $v$. the lowest quartile of meat consumption in prospective studies.

cancer. Two studies (Willett et al. 1990; Giovannucci et al. 1994) have shown significant evidence of increased trends of colorectal cancer risk with red meat consumption and one a significant reduction in risk from white meat (Willett et al. 1990). Table 2 shows that a significant elevated risk for processed meat consumption and large bowel cancer was shown in two studies (Willett et al. 1990; Goldbohm et al. 1994).

Fig. 7 shows relative risks for highest $v$. lowest classifications of red, processed and white meat consumption, and confidence intervals where these are published. Though the majority of studies have wide confidence intervals and therefore non-significant results, 
Table 3. Trends in risk of large bowel cancer in prospective studies by quantile of fibre and vegetables

\begin{tabular}{|c|c|c|c|}
\hline Total number & $\begin{array}{l}\text { Significant } \\
\text { positive } \\
\text { association }\end{array}$ & $\begin{array}{l}\text { Significant } \\
\text { inverse } \\
\text { association }\end{array}$ & Effects not significant \\
\hline $\begin{array}{c}\text { Fibre } \\
7\end{array}$ & none & $\begin{array}{l}\text { Heilbrun et al. } 1989 \\
\text { Thun et al. } 1992\end{array}$ & $\begin{array}{l}\text { Morgan et al. } 1988 \\
\text { Willett et al. } 1990 \\
\text { Giovannucci et al. } 1994 \\
\text { Goldbohm et al. } 1994 \\
\text { Steinmetz et al. } 1994\end{array}$ \\
\hline $\begin{array}{l}\text { Vegetables } \\
6\end{array}$ & none & $\begin{array}{l}\text { Morgan et al. } 1988 \\
\text { Shibata et al. } 1992 \text { (women) } \\
\text { Thun et al. } 1992 \\
\text { Steinmetz et al. } 1994\end{array}$ & $\begin{array}{l}\text { Hirayama, } 1981 \\
\text { Shibata et al. } 1992 \text { (men) } \\
\text { Giovannucci et al. } 1994\end{array}$ \\
\hline
\end{tabular}

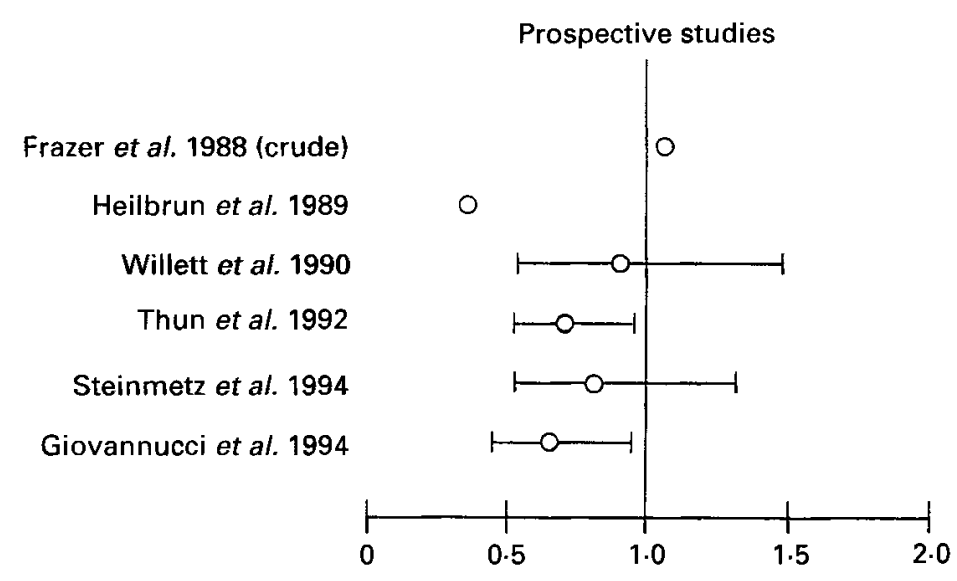

Fig. 8. Relative risks for colon cancer and $95 \%$ confidence intervals for the highest $v$. the lowest quartile of fibre consumption in prospective studies.

there is a trend for red and processed meats to increase colon cancer risks, and some evidence that white meat is associated with either no effect, or reduction in risk.

Seven studies have assessed fibre or fibre-containing foods, and two (Heilbrun et al. 1989; Thun et al. 1992) detected a significant inverse protective trend between dietary fibre and colorectal incidence. No study demonstrated an enhanced risk (Table 3). Five did not detect significant trends, but in one (Willett et al. 1990) fibre was protective in high fat consumers and in two a non-significant inverse trend (Giovannucci et al. 1994; Steinmetz et al. 1994) was shown. The lack of association with trends in bowel cancer in the Male Health Professionals Study of Giovannucci et al. (1994) occurred despite higher fibre consumption in the lowest risk group (Fig. 8). Relative risks for this and other studies which report them also tend to be less than 1.00 and range from 0.9 to 0.5 in individuals classified in the upper ends of the distribution of fibre intake (Fig. 8). No study has reported bowel cancer risk using analyses of dietary fibre as NSP. No prospective study has attempted to measure starch consumption, although cereals appeared to be inversely associated in the study of Hirayama (1981). 


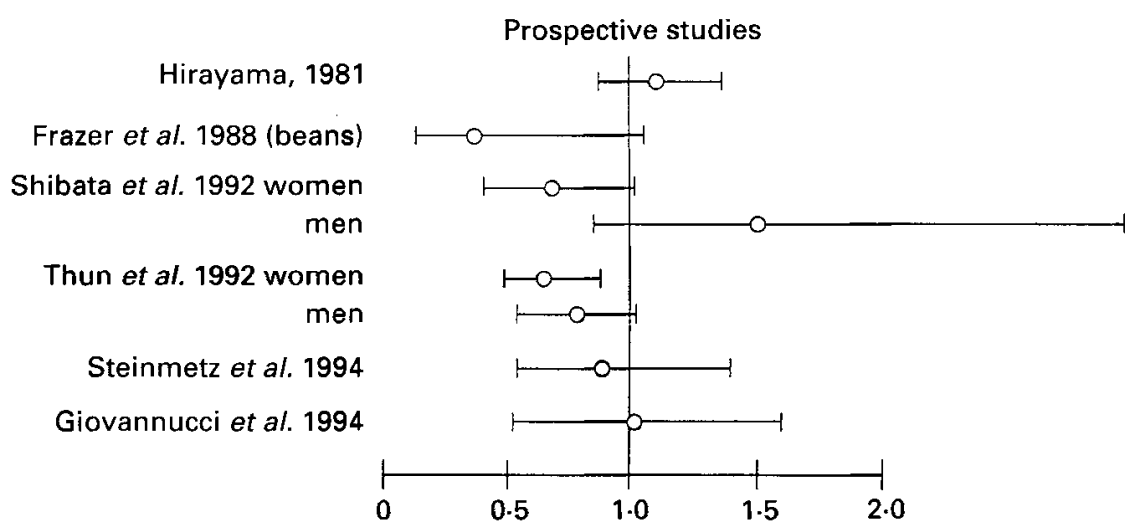

Fig. 9. Relative risks for colon cancer and $95 \%$ confidence intervals for the highest $v$. the lowest quartile of vegetable consumption in prospective studies

Six prospective studies have investigated vegetable consumption. None have reported increased trends in risk with increased consumption, and three have shown significant protective effects (Morgan et al. 1988; Thun et al. 1992; Steinmetz et al. 1994). In one, significant protective effects were shown in women and a non-significant higher risk in men (Shibata et al. 1992). A non-significant higher risk was also shown in the study of Hirayama (1981), Table 3. Willett et al. (1990) did not report vegetable consumption, although a failure to find significant effects with 'vegetable fibre' probably indicates no significant effects. No significant findings were shown in the study of Giovannucci et al. (1994). Fig. 5 shows relative risks in the individuals classified in highest $v$. lowest categories of consumption; these are generally in the direction of lower risk with increased consumption and relative risks in the order of $0.9-0.5$.

Of the few prospective studies published so far, results to date are therefore not entirely consistent with those obtained from cross-sectional and case-control studies, suggesting a markedly increased risk for greater total meat and fat consumption. Only the studies of US health professionals (Willett et al. 1990; Giovannucci et al. 1994) are strongly supportive of a role for meat, and that for red meat, although the evidence so far suggests that processed meat consumption also appears to increase the risk. The US health professional studies have not detected an inverse role for vegetables and no role for fibre was detected in women, although generally the evidence relating vegetable and NSP intake is more consistently associated with protection from large bowel cancer. Overall, there is suggestive evidence of a slightly increased risk for fat, red meat and processed meat and a reduced risk for vegetables and NSP. However, the magnitudes of the relative risks are low and generally non-significant, in the order of $1-2$ for increased risk and 1-0.5 for reduced risk (Figs 6-9). This compares with relative risks of 15 for smoking and lung cancer. More good quality data are required, and will not be forthcoming for 5-10 years.

\section{Studies in patients with adenomatous polyps}

The dietary habits of patients with polyps are probably related to risk of cancer, although the risk of transformation for an individual adenoma is low. There are a number of casecontrol studies of dietary factors (Table 4). The majority have yielded non-significant associations. Two prospective studies examining macronutrients have so far been conducted (Stemmermann et al. 1988; Giovannucci et al. 1992) and a number of intervention studies are in progress (see p. 212). The prospective study of Giovannucci et al. (1992), on 7284 male 
Table 4. Summary of trends in risk from adenomatous polyps case-control and prospective* studies by quantile

\begin{tabular}{|c|c|c|c|c|}
\hline Item & $\begin{array}{c}\text { Total } \\
\text { number }\end{array}$ & Positive association & Inverse association & Not significant \\
\hline Meat & 7 & $\begin{array}{l}{ }^{*} \text { Giovannucci et al. } 1992 \\
\text { (red) } \\
\text { Kono et al. } 1993\end{array}$ & Neugut et al. 1993 (chicken) & $\begin{array}{l}\text { Neugut et al. } 1993 \text { (red) } \\
\text { Hoff et al. } 1986 \\
\text { Macquart-Moulin et al. } \\
1987 \\
\text { Sandler et al. } 1993 \\
\text { Benito et al. } 1993\end{array}$ \\
\hline Protein & 6 & & & $\begin{array}{l}\text { Hoff et al. } 1986 \\
\text { Macquart-Moulin et al. } \\
1987 \\
\text { *Giovannucci et al. } 1992 \\
\text { *Stemmermann et al. } \\
1988 \\
\text { Neugut et al. } 1993 \\
\text { Sandler et al. } 1993\end{array}$ \\
\hline Fat & 6 & $\begin{array}{l}\text { Hoff et al. } 1986 \\
\text { Sandler et al. } 1993 \\
\text { (females) } \\
\text { *Giovannucci et al. } 1992 \\
\text { Little et al. } 1991 \\
\quad \text { (polyunsaturates) }\end{array}$ & Neugut et al. 1993 (males) & $\begin{array}{l}\text { Neugut et al. } 1993 \\
\text { (females) } \\
\text { Sandler et al. } 1993 \\
\text { (males) } \\
\text { Macquart-Moulin et al. } \\
1987 \\
\text { *Stemmermann et al. } \\
1988\end{array}$ \\
\hline Fibre & 5 & & $\begin{array}{l}\text { Neugut et al. } 1993 \text { (males) } \\
\text { Little et al. } 1991 \\
{ }^{*} \text { Giovannucci et al. } 1992\end{array}$ & $\begin{array}{l}\text { Neugut et al. } 1993 \\
\text { (females) } \\
\text { Hoff et al. } 1986 \\
\text { Sandler et al. } 1993\end{array}$ \\
\hline Vegetables & 5 & & $\begin{array}{l}\text { Hoff et al. } 1986 \\
\text { *Giovannucci et al. } 1992 \\
\text { Sandler et al. } 1993 \text { (women) } \\
\text { Benito et al. } 1993\end{array}$ & $\begin{array}{l}\text { Macquart-Moulin et al. } \\
1987 \\
\text { Neugut et al. } 1993 \\
\text { Sandler et al. } 1993 \\
\text { (men) }\end{array}$ \\
\hline
\end{tabular}

health professionals, showed positive associations with red meat and fat (including saturates and monounsaturates but not polyunsaturates), and inverse associations with total carbohydrates, dietary fibre, and dietary fibre from cereals and vegetables.

\section{OTHER DIETARY FACTORS}

\section{Calcium}

Interest in calcium arose as a result of the hypothesis that high intakes $(2 \mathrm{~g} / \mathrm{d}$ or more $)$ would inhibit the toxic effects of free fatty acids entering the large bowel (Newmark et al. (1984), see p. 219). UK average intakes of calcium from food are about $700 \mathrm{mg} / \mathrm{d}$, so supplements are required to attain these high levels. Several intervention studies with calcium are in progress to assess recurrence of polyps in patients at high risk of colon cancer but no results have yet been reported.

Potter et al. (1994) have reviewed the epidemiological evidence and suggested that a protective association with calcium is evident. To date, six cohort studies have reported calcium intake in relation to risk of colorectal cancer. All are suggestive of a reduced risk with high intakes although relative risks were not universally significantly reduced (Fig. 10). 
Garland et al. 1985

Wu et al. 1987

Stemmermann et al. 1984

Bostick et al. 1993 (unadjusted)

(multivariate)

Slob et al. 1993 (total GI) men

women

Kampman et al. 1994

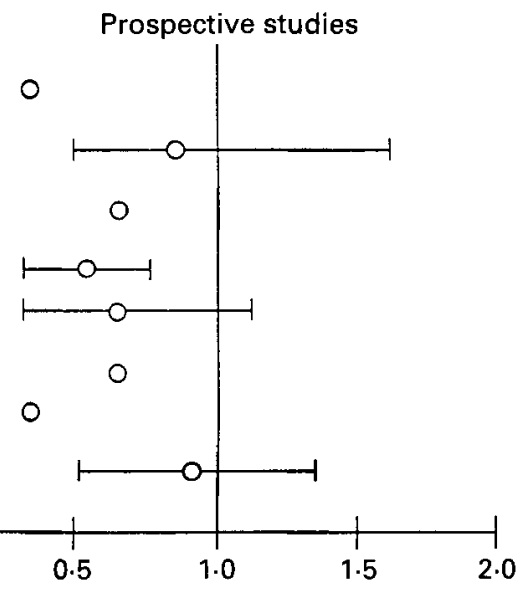

Fig. 10. Relative risks for colon cancer and $95 \%$ confidence intervals for the highest $v$. the lowest quartile of calcium consumption in prospective studies.

Relative risks in the study of Slob et al. (1993) refer to all gastrointestinal (including stomach) cancer because there were too few cases for a separate analysis. Women who died of colorectal cancer had, however, consumed less calcium than the rest of the population. Bostick et al. (1993) were unable to detect significant differences in multivariate analyses of a cohort study. Univariate results for calcium in food did not show a significant protective effect, but cases had consumed $209 \mathrm{mg}$ calcium/d from supplements whereas controls had consumed $283 \mathrm{mg} / \mathrm{d}$ from supplements, and these differences were significant. Overall therefore, results are suggestive but effects may arise from supplements rather than food.

\section{Iron}

Free iron is a well accepted catalyst in the Fenton reaction which yields hydroxyl radicals and it has been proposed that oxidative damage occurs in the colon, which can be suppressed by the presence of phytic acid, a known chelator of iron (Graf \& Eaton, 1993). Animal studies have shown that very high doses of iron $(580 \mathrm{mg} / \mathrm{kg}$ diet, ten times greater than human intakes) induce tumours, and that tumour yield is reduced if phytate is added to the diet (Nelson et al. 1989; Ullah, 1990). However, subsequently it has been shown that increased iron does not increase lipid peroxidation products in a rodent colon cancer model (Kuratko \& Pence, 1995).

Of three epidemiological studies that have measured iron stores only the study of Nelson et al. (1994) assessed iron status from serum ferritin levels, which reflect body stores. In this case-control study there was no significant increase in relative risk for cancer patients (who may have reduced stores due to gastrointestinal bleeding), but adenoma patients at the upper end of the distribution in ferritin levels had a significant elevated relative risk of $4 \cdot 3$

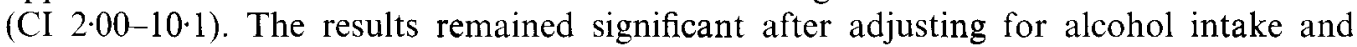
excluding individuals with serum ferritin levels in excess of $400 \mathrm{ng} / \mathrm{ml}$. Two studies have measured transferrin saturation, although levels can be elevated secondarily to chronic inflammation. The study of Stevens et al. (1994) was based on a relatively small cohort and separate analyses for colon cancer were not possible. Elevated transferrin saturation levels were associated with increased risk of all cancer, either incidence or mortality. In a large Finnish cohort, elevated risks of 3.04 (CI 1.64-5.62) for colorectal cancer and cancer at all sites $(1 \cdot 43$, CI 1.16-1.77) were evident in those individuals classified as having higher levels of transferrin saturation (Knekt et al. 1989). 
Iron intake was measured in four case-control studies, three in polyp patients and one in rectal cancer patients. They have generally shown no significant effects or inverse trends (Hoff et al. 1986), but supplemental intakes may not have been recorded (quoted from Nelson et al. 1994). In summary, although high iron stores are associated with increased risk, these may not be related to increased intake, and data on intake from prospective studies are required to confirm a role for iron in colorectal cancer.

\section{Vitamin $D$}

Vitamin $D$ is classically associated with calcium homeostasis but a more fundamental role in controlling cell growth and differentiation has more recently emerged. Garland et al. $(1985,1989)$ found significant protective effects against colon cancer for both dietary vitamin $D$ and serum 25 -hydroxyvitamin $D$ in two separate cohorts. Later epidemiological evidence is less consistent, with a non-significant effect for vitamin D shown in one cohort and in two case-control studies (Potter et al. 1994).

\section{Vitamins $E$ and $C$}

One reason often put forward for the protective effect of vegetables against cancer is that vegetables and fruits are the major source of vitamin $\mathrm{C}(70 \%$ in British diets) and of vitamin $\mathrm{E}$. These are able to inhibit the formation of the surrogate for carcinogenic $N$ nitroso compounds, $N$-nitrosoproline, and possibly the mutagen isolated from faeces, fecapentaene. Like $\beta$-carotene, they are part of the antioxidant defence, which may be important in preventing spontaneous point mutations.

Using pooled data from five prospective cohorts, however, relative risks for the top quartile of serum vitamin $\mathrm{E}$ adjusted for serum cholesterol were not significant $(0 \cdot 7 ; 95 \%$ CI $0 \cdot 4-1 \cdot 1$ ), and there were no significant trends in risk across quartiles (Longnecker et al. 1992). Relative risks were significantly reduced $(0 \cdot 3$; CI $0 \cdot 1-0 \cdot 8)$ when only those patients with an interval of between 5 and 7.5 years from blood collection to diagnosis were included. At longer intervals the relative risk increased to $1 \cdot 2$ (CI $0 \cdot 4-3 \cdot 3)$. The authors concluded that the evidence for any protective effect was weak, although evidence from larger prospective studies was required to determine whether vitamin $\mathrm{E}$ has a modest protective effect in colorectal cancer (Longnecker et al. 1992). A later cohort (Bostick et al. 1993 ) reported a significant reduction in relative risk of colon cancer for women less than 60 years old who had taken vitamin E supplements, although no effects were found for dietary vitamin $\mathrm{E}$ alone. Logistically, there is little information on prospective levels of plasma vitamin $\mathrm{C}$ in relation to cancer and only the Basel prospective study (Stahelin et al. 1991) has assessed plasma vitamin C levels in relation to cancer, and the cohort size is too small to permit a separate analysis for colon cancer.

There are many other constituents of plants (folate, flavonoids, NSP, glucosinolates, carotenoids) and these could be of more relevance than these vitamins in colorectal cancer (see pp. 212-214, 218, 224-226).

\section{Folate}

Folate and vitamin $\mathrm{B}_{12}$ are critical elements in $-\mathrm{CH}_{3}$ group metabolism and thus in thymidine and DNA repair. In women using oral contraceptives, localized folate deficiency was the suggested reason for the presence of dysplasia in the cervix, and intervention with folate has been shown to improve dysplasia scores (Whitehead et al. 1973; Butterworth et al. 1982). Bronchial metaplasia has also been shown to be improved in smokers given supplements of folate and vitamin $\mathrm{B}_{12}$ (Heimberger et al. 1988).

Connexions with large bowel dysplasia and hence cancer risk began with a retrospective case-control study in which folate supplementation was associated with a non-significant 
lower incidence of dysplasia in ulcerative colitic patients, who are at high risk of colon cancer (Lashner et al. 1989). In a later study, risk of dysplasia in ulcerative colitis was inversely associated with red cell folate levels (Lashner, 1993). No prospective study has reported on the role of folate in colorectal cancer, but relative deficiency has been implicated in another large bowel disorder that carries increased risk of cancer, adenomatous polyps. Giovannucci et al. (1993b) found significant $(P=0.02)$ inverse trends in risk with increasing intake, with relative risks of 0.71 (CI $0.56-0.89$ ) for colorectal polyps in individuals in the top quintile of folate intake. The median levels of energy adjusted folate intakes in men and women $(847$ and $711 \mu \mathrm{g} / \mathrm{d})$ would not have been achievable from dietary sources (average UK intake $220 \mu \mathrm{g} / \mathrm{d}$ ) and must have been largely derived from supplements. Folate from food alone was not significantly related to adenomas.

Meat is the major source of methionine which is the precursor of S-adenosylmethionine, the methyl donor for DNA methylation. S-adenosylmethionine is regenerated using folate. Despite their earlier positive associations found between adenomas and meat consumption (Giovannucci et al. 1992) the authors demonstrated inverse associations with methionine intake. No information on the contribution of supplements to total methionine intake is given in the paper, but energy adjusted intakes in the top quintile were $2.5-2.7 \mathrm{~g} / \mathrm{d}$, compared with WHO requirements of approximately $1.0 \mathrm{~g} / \mathrm{d}$ for methionine and cysteine combined (WHO, 1973). Positive associations with alcohol, capable of diminishing hepatic S-adenosylmethionine, were also found, and the authors proposed that all three were related to colorectal cancer risk via hypomethylation of DNA (Giovannucci et al. 1993 b).

\section{Alcohol}

In vitro studies suggest that alcohol is not a direct carcinogen, although acetaldehyde, the main metabolic product in humans, is a known carcinogen. Alcohol free extracts of some beverages are also genotoxic (IARC, 1988). Alcohol consumption is particularly linked with high risk of rectal, rather than colon, cancer. The prospective Kaiser Permanente study, for example, showed a stronger $(P=0.03)$ trend for alcohol use in rectal cancer than in colon cancer $(P=0 \cdot 11)$. Relative risks in people consuming three or more drinks per day were $3.17(1.05-9.57)$ for rectal cancer but non-significantly elevated in colon cancer $(1 \cdot 17$; 0.92-3.19) (Klatsky et al. 1988). The IARC working group was unable to draw conclusions about the role of alcoholic beverages in the causation of colon cancer, and found the evidence linking rectal cancer and consumption of alcohol, mainly beer, suggestive but not conclusive (IARC, 1988). Potter et al. (1994) suggested that alcohol consumption is independently linked to colon cancer, and noted that seven out of fifteen general population studies showed positive associations. However, the meta-analysis of Longnecker et al. (1990) led to an overall relative risk of only $1 \cdot 1(1 \cdot 05-1 \cdot 14)$. More recently, Doll et al. (1993) also found no consensus on the interpretation of existing observations, except that if a risk does exist for colorectal cancer it is less than 2-fold, even with high levels of alcohol consumption.

\section{Energy balance and exercise}

There is an independent effect of total energy restriction on chemically induced carcinogenesis of the large bowel in rodents (Rogers et al. 1993). However, there appears to be little effect of energy intake in human cohort studies, where this is reported (Willett et al. 1990; Giovannucci et al. 1994). In humans, energy intake and expenditure, and hence energy balance, are interrelated, so that alterations in body size or expenditure might be expected to be related to colon cancer risk. Potter et al. (1994) were unable to establish a consistent effect of body size on colon cancer risk, but there were consistent protective effects of increased energy expenditure, in case control and cohort studies assessed from 
both reported occupations and recreational activity (Potter et al. 1994). Direct evidence is available from a cohort study of Japanese migrants, in which physical activity and heart rate were measured. There were significant $(P=0.03)$ inverse trends in relative risk with resting heart rate, and significantly reduced relative risks in individuals classified in the upper third of physical activity $(0.71 ; 0.51-0.99)$ (Severson et al. 1989).

Although the effect of exercise is usually attributed to reduced transit time through the large gut (Gerhardsson de Verdier et al. 1990), there is no effect of exercise on transit time in studies in which food intake has been controlled (Bingham \& Cummings, 1989). Since relative risks for cancers at sites other than the large bowel are also reduced by exercise, a more general mechanism for a protective effect is likely. Increased serum triglycerides and glucose have been suggested to be the common factors linking diet, obesity and lack of exercise to increased risk of colon cancer. Higher levels of serum triglycerides were found to be associated with increased risk of polyp recurrence, and higher levels of circulating insulin or glucose may be associated with increased neoplastic cell growth (McKeownEyssen, 1994).

\section{INTERVENTION STUDIES}

Intervention studies so far have mainly been confined to assessing the effect of intervention on recurrence of polyps in high risk groups of patients with familial adenomatous polyposis, and of patients with adenomatous polyps. There are several large intervention studies in progress and dietary items being tested include supplements of wheat bran, ispagula, resistant starch, $\beta$-carotene and other antioxidant vitamins found in vegetables, calcium, and reduction in fat.

Very large supplements of vitamin A (30000 i.u.), C (1 g) and E (70 mg) reduced proliferation in upper crypt compartments in 23 patients compared with 23 patients given placebo, but there was no significant effect on polyp recurrence in patients given $400 \mathrm{mg}$ doses of vitamins $\mathrm{C}$ and $\mathrm{E}$ compared with a placebo of lactose (McKeown-Eyssen et al. 1988; Paganelli et al. 1992). In an intervention study of patients with familial adenomatous polyposis, rectal polyp recurrence was inhibited to a greater extent by supplements of bran with vitamins $C$ and $E$ than by supplements of these vitamins alone (Decosse et al. 1989). In 300 polyp patients studied in Australia, supplements of $20 \mathrm{mg} \beta$-carotene increased polyp recurrence, particularly large polyps (MacLennan et al. 1991, 1995). Reduction in fat intake was not associated with an overall reduction in polyp numbers, although the combination of a low fat diet and $25 \mathrm{~g}$ wheat bran for 4 years did lead to a significant reduction in the frequency of large adenomas (MacLennan et al. 1995). A large multicentre trial from the USA has shown that supplements of $25 \mathrm{mg} \beta$-carotene, $1 \mathrm{~g}$ vitamin $\mathrm{C}$ or $400 \mathrm{mg}$ vitamin $\mathrm{E}$ had no effect on polyp recurrence (Greenberg et al. 1994). A trial of Finnish smokers also showed no effect of large supplements of $20 \mathrm{mg} \beta$-carotene or $50 \mathrm{mg}$ vitamin E per day on the incidence of large bowel cancer (ATBC, 1994). So far, therefore, any protective effect of vegetables in colon cancer cannot be attributed to antioxidant vitamins, and supplements of $\beta$-carotene may increase the risk. In the two studies that have so far reported results, supplements of NSP as bran seemed to reduce risk.

\section{DIET AND CHEMICALLY INDUCED CARCINOGENESIS}

\section{NON-STARCH POLYSACCHARIDES, STARCH}

The effect of purified sources of dietary fibre on chemically initiated colorectal cancer in animals has been investigated in a large number of studies. Owing to heterogeneity of experimental protocols, coupled with incorrect or non-existent statistical analysis, Klurfeld 
(1990) was unable to interpret the existing evidence to support a protective effect for 'insoluble' fibre (bran, cellulose etc.) in chemically initiated colorectal cancer. In contrast, a collation of overall findings of experimental studies by the Federation of American Societies for Experimental Biology (Pilch, 1987) showed that bran appeared to have a consistently protective effect against chemical carcinogenesis. Bran decreased the number of tumours in 13 out of 17 studies, and increased the number of tumours compared with control levels in only one study. Cellulose also appeared protective in six of nine studies, with no significant difference in three. However, 'soluble fibres' are associated with tumour enhancement (Jacobs, 1990). This may be related to the fact that soluble fibres are rapidly fermented in the caecum, whereas insoluble fibres survive for longer (see pp. 224-227). Pectin also appears to have differing effects in humans to rodents, at least on bacterial enzyme activity (see pp. 219-220). In addition, the relevance of these studies to normal human diets containing comparatively low levels of mixed NSP is uncertain.

The effect of starch on chemical carcinogenesis has not been investigated so intensively, and there is only one report in the literature as yet. Using potato starch granules as the source of resistant starch, tumorigenesis induced by dimethylhydrazine was increased in rodents, but suppressed when wheat bran was added (Young et al. 1996).

\section{FAT, ENERGY}

Energy restriction has a powerful effect in reducing tumorigenesis at most sites via a number of postulated mechanisms such as reduced growth in all tissues, alteration of carcinogen metabolism, and reduction in oxidative damage to DNA. The restrictions required are $>10 \%$ of total intake, and the converse (increased tumorigenesis with increasing intake) is not clearly demonstrated because rodents will not voluntarily ingest excess energy (Rogers et al. 1993).

There is some debate as to whether high fat diets or high energy diets (usually a consequence of high fat diets) are more important. For example, in a combined analysis of fat, protein and energy intake, there were no significant effects of total fat on either initiation or promotion on azoxymethane induced tumours of the large intestine. Only energy intake was significantly associated (Clinton et al. 1992). In contrast, independent effects of fat and energy were proposed in a study where a significant increase in the number of azoxymethane induced tumours was found in animals fed high fat (as maize oil) ad lib. diets, compared with animals fed low fat restricted, low fat ad lib. and high fat restricted (by $20 \%$ ) diets (Steinbach et al. 1993).

Any effect of total fat is also likely to be modulated by the effects of NSP and starch, in addition to energy and type of fat, and to depend on the use of direct acting carcinogens (e.g. $N$-methyl- $N^{\prime}$-nitro- $N$-nitrosoguanidine) or indirect ones, such as azoxymethane. No consistent effects of total fat on $N$-methyl- $N^{\prime}$-nitro- $N$-nitrosoguanidine tumours at high levels of fibre were found, for example, whereas tumour incidence increased with high fat, low fibre diets (Sinkeldam et al. 1990).

\section{n-3 AND n-6 FATTY ACIDS}

The type of fat consumed seems to be important in colorectal tumorigenesis, $\mathbf{n}-6$ fatty acids being required to at least $5 \%$ energy to satisfy tumour requirements. Higher levels may induce a greater number of tumours (Reddy \& Sugie, 1988). At equivalent levels, n-3 fatty acids are associated with lower tumour incidence. Reddy \& Sugie (1988) and Reddy et al. (1991), for example, found higher levels of tumours in rats fed $24 \%$ maize oil than in rats fed $18 \%$ menhaden oil plus $5 \%$ maize oil. However, the effect of n-3 and n-6 fatty acids in 
reducing and increasing tumorigenesis respectively is not as consistent in the animal models of colon cancer as it is in models of mammary cancer (Rogers et al. 1993).

\section{PROTEIN AND MEAT}

Visek (1978) proposed a role for high protein diets in colorectal cancer and showed that tumour yield is increased in animals fed high protein diets (Topping \& Visek, 1976). However, there have been few investigations in animals and one later study has found no effect of protein on either the total number of tumours or percentages of animals with tumours, apart from an increase in polyploid types of tumour (Clinton et al. 1992). Cooked casein (and sugar) has been shown to increase colonic microadenoma in rodents (Corpet et al. 1990) and low protein diets are known to reduce the activity of phase I enzymes (see pp. 224-225). There are conflicting reports of the effects of high meat diets in modulating promotion of colon carcinogenesis in animal models (Reddy et al. 1976; Pence et al. 1995) but meat may be more important in initiation rather than promotion (see pp. 222-224). No effect of raw or grilled beef has been shown compared with soya protein (Clinton et al. 1979).

\section{POTENTIAL MECHANISMS}

At least 10 different dietary factors are linked with colorectal cancer. Plausible hypotheses involving dietary factors in the aetiology of large bowel cancer mainly concern events in the lumen of the large bowel and the metabolism of the colonic flora, which in turn is controlled by diet. In addition, genotoxins are modified by phase I and II enzymes and colonic epithelial cells are exposed to systemic factors such as n-3 fatty acids.

\section{THE COLONIC FLORA AND FERMENTATION}

The colon is host to a large and diverse commensal flora of anaerobic bacteria. With more than 400 species (Feingold et al. 1983) the colonic flora has considerable flexibility and potential for metabolic transformations. Enzymes are readily induced by changes in the metabolic environment and a wide variety of substances can be hydrolysed, reduced, degraded, or synthesized. The major control on the metabolic environment of the flora is via residues entering the large gut from the small bowel. These in turn are determined by dietary intakes, particularly protein and carbohydrate. Lipids in the form of bile acids, phospholipids and fatty acids are also metabolized by the flora. Sulphate and nitrate arising directly or indirectly from diet are also of considerable current interest.

\section{Carbohydrate}

Carbohydrate entering the large bowel stimulates anaerobic fermentation, leading to the production of short chain fatty acids (SCFA), acetate, propionate, and butyrate, gas, and an increase in microbial cell mass (biomass). The SCFA are absorbed by the intestinal mucosa where they stimulate sodium absorption and bicarbonate production (Cummings, $1981 b$ ). Sugars such as lactose in lactase deficient individuals, and oligosaccharides such as fructooligosaccharides, and inulin are substrates for fermentation, but normally it is the polysaccharides that are quantitatively most important. Of these, only $12 \mathrm{~g}$ NSP ('fibre') is available in western diets, an amount that is insufficient to account for the known amounts of SCFA produced (Cummings, 1981 b). However, studies in man have shown that a significant amount of starch escapes digestion in the small gut, depending on the physical form of the food eaten, the granule type, and how it is cooked and processed (Englyst et al. 1992). This starch, resistant starch, reaches the large bowel and is also a substrate for fermentation (see also Chapter 1). 


\section{Dilution, stool weight and transit time}

Carbohydrate fermentation has a number of implications for protection against large bowel cancer. The stimulation of bacterial growth, together with water binding to residual unfermented NSP, leads to an increase in stool weight, dilution of colonic contents and faster transit time through the large gut (Cummings, 1981 a; McBurney et al. 1985; Phillips et al. 1995). This may reduce contact of genotoxins with mucosal cells, and supplements of bran have been found to reduce faecal mutagenicity (Venitt et al. 1986; Reddy et al. 1987). Long transit time has not been related to large bowel cancer risk, but there is a strong inverse association between high stool weight and colorectal cancer incidence (Cummings et al. 1981, 1992). Low stool weight leads to constipation, which together with use of cathartics are risk factors for colorectal cancer. Odds ratios are 1.48 (1.32-1.66) and 1.46 (1.33-1.61) respectively, with attributable risks for colon cancer of $4.4 \%$ in the US population (Sonnenberg \& Muller, 1993). High stool weight is also associated with less crosslinking during passage of a DNA surrogate through the gut (Bingham et al. 1996). The association between low stool weight and bowel disease and the linear relationship between NSP consumption and stool weight, with a $5 \mathrm{~g}$ increase for every $1 \mathrm{~g} \mathrm{NSP}$ consumed, is the basis for UK and WHO recommendations of an $18 \mathrm{~g}$ population average intake of NSP, a $50 \%$ increase for the UK and most Western populations (World Health Organization, 1990; Department of Health, 1991)

\section{Butyrate}

During fermentation, approximately 60,20 and $20 \%$ molar ratios of acetate, propionate and butyrate are formed in the large gut (Cummings, 1981 b). Molar ratios can however be varied according to the substrate. In in vitro batch cultures, $29 \%$ of butyrate can be produced from starch, compared with 2-8\% from NSP sources (Englyst et al. 1987), and in vivo molar ratios of butyrate can be made to increase by $50 \%$ by feeding the glucosidase inhibitor acarbose (Scheppach et al. 1988). Starch may therefore be a better source of butyrate than NSP.

SCFA are absorbed from the large gut (Cummings et al. 1987), enhancing the functional capacity of the epithelium (Scheppach et al. 1990). Less butyrate is found in the portal vein, and in the isolated human colonocyte butyrate accounts for about $75 \%$ of oxygen consumption. Glucose is able to replace butyrate to a lesser extent in the proximal colon compared with the distal colon (Roediger, 1980). This suggests that the sigmoid and distal colon are particularly dependent on adequate supplies of butyrate. These are the areas of the gut where most tumours arise.

Because of this nutritional SCFA function, indices of proliferation induced by resistant starch or NSP are necessarily greater than levels found on baseline semi-purified diets in some rodent studies. Incubation of caecal biopsies with SCFA increased the labelling index in the lower crypt compartments of human caecal biopsies from patients maintained on low dietary fibre diets ( $18 \mathrm{~g}$, equivalent to $12 \mathrm{~g} \mathrm{NSP}$ ). Butyrate and propionate were more effective than acetate. However no expansion of the proliferative compartment to the crypt surface was observed (Scheppach et al. 1992). NSP and resistant starch, which are slowly fermented because of their stereochemistry, are more likely to reach the distal colon before being fermented into SCFA. Hence slowly fermented resistant starch and NSP sources are likely to be physiologically more important in the distal bowel than NSP sources such as pectin and guar gum which are rapidly fermented in the caecum.

Butyrate was suggested as a protective agent against colon cancer in 1981 (Cummings et al. 1981). Two studies using direct acting carcinogens in rodents have not shown a protective effect against carcinogenesis of large amounts of butyrate added to drinking 
water (Freeman, 1986; Deschner et al. 1990). These experiments were conducted with rodents fed on Purina chow which, with its $4.5 \%$ crude fibre content, would have been equivalent to $20 \%$ by weight NSP or an intake of 100-200 g NSP per day in human terms. This would have already provided butyrate markedly in excess of rat or human needs.

In cultured cell lines, butyrate is a well recognized antiproliferative agent, arresting cell growth in $G_{1}$, and inducing differentiation. Histone deacetylase is inhibited and other SCFA are much less active in this respect (Kruh, 1982). Alterations in gene expression occur and chromatin accessibility to DNA repair enzymes is altered (Smith, 1986). Rodent studies have shown that luminal butyrate levels are inversely associated with colonic cell proliferation, and positively associated with histone acetylation (Boffa et al. 1992). High starch diets, providing substrates for increased amounts of butyrate in the lumen, have been shown to reduce proliferative activity in the colon of mice and in humans (Caderni et al. 1989; Van Munster et al. 1994).

In addition to its effect on cell growth and differentiation, butyrate stimulates cytoskeletal organization, and alters gene expression. In colonic cells, butyrate induction of placentallike alkaline phosphatase is regulated by increased message levels which occur with differentiation. In LS174T cells, the $5^{\prime}$ flanking regions of the placenta-like alkaline phosphatase gene were found to contain cis acting elements which regulate placenta-like alkaline phosphatase expression (Kim et al. 1994). In Swiss 3 T3 cells, arrest of cell growth and differentiation by butyrate is associated with a reduction in c myc, p53, thymidine kinase and induction of cfos and aP2 (Toscani et al. 1988). Paraskeva and colleagues (Hague et al. 1993) have suggested that butyrate induces apoptosis, or programmed cell death, which may account for its role in reducing proliferation.

\section{Fat, bile acids, $\mathrm{pH}$}

High fat diets increase faecal mutagenicity in humans (Nair et al. 1990) and lead to increased levels of bile acids in the colonic lumen (Cummings et al. 1978). The secondary bile acid deoxycholic acid is known to be damaging to the mucosa and a promoter of bowel cancer in rodent systems (Narisawa et al. 1974). Bile acids alone are unlikely to affect colon cancer risk because there is no difference in faecal bile acid excretion either between cases and healthy matched controls, or between individuals living in high risk areas compared with low ones (Setchell et al. 1987). However, because of their insolubility, bile acids are less damaging at low pH (Rafter et al. 1986). During fermentation, the SCFA produced reduce luminal $\mathrm{pH}$. Bacterial $7 \alpha$-dehydroxylase activity and hence conversion of primary to secondary bile acids deoxycholic and lithocholic acids is also inhibited (Midvedt \& Norman, 1968; Van Munster et al. 1994).

\section{Diacylglycerol}

A role for bile acids in promotion may be through diacylglycerol (DAG), one of two intracellular messengers formed from phosphatidyl inositol. DAG increases the affinity of protein kinase $\mathrm{C}$ for calcium and renders it active at physiological levels of this ion, phosphorylating serine and threonine residues in many target organs (Nishizuka, 1986). Phorbol esters are well known promoters because they resemble DAG but are not degraded.

The fatty acid composition of DAG is modified by intake of dietary lipid, and it is possible that a change in the type of DAG may affect activation of protein kinase C. Methyl group deficiency is also able to increase DAG levels, at least in the liver (Rogers et al. 1993). Increased levels of protein kinase $C$ have been reported in colonic tumour tissue (Guillem et al. 1987) and this group of workers has also shown that DAG production from 
phosphatidylcholine is enhanced in human fermentation systems by the presence of deoxycholic acid (Morotomi et al. 1990). Total faecal DAG levels have been shown to be reduced by a supplement of $15 \mathrm{~g}$ wheat bran in women (Reddy et al. 1994).

\section{Calcium}

Another proposal is that damage to the colonic mucosa by free fatty acids and bile acids arising from a high fat diet can also be ameliorated by supplements of calcium, which form insoluble soaps in the colon, and prevent the consequent epithelial cell proliferation (Newmark et al. 1984). The authors calculated that 1.5-2 g of calcium per day are needed to neutralize the estimated $32 \mathrm{~mm}$ of fatty acids and phosphorus entering the colon. A number of relatively short term intervention trials with these large doses of calcium, measuring proliferation by labelling index with tritiated thymidine from rectal biopsies, have been started, usually in patients with polyps from whom biopsies can be more easily obtained. There have been inconsistent effects on overall mucosal cell proliferation, with some studies showing increased labelling indices, others reduced indices, and in others normalized turnover rates in the upper crypt (Kleibeuker et al. 1993; Zimmerman, 1993; Kubben et al. 1994; Bostick et al. 1995; Weisgerber et al. 1995).

\section{Fecapentaenes}

Fecapentaenes, compounds with a central pentaene structure and a chain length of 12 or $14 \mathrm{C}$, are direct acting alkylating mutagens (Gupta et al. 1984). They are known to be produced by Bacteroides spp., the commonest species in the human colon, probably from plasmalogen phospholipids (Van Tassell et al. 1989) which are structural components of lipid bilayers and which have their own unique pathway of biosynthesis. Cells of the heart, brain and muscle are especially rich in plasmalogens (Garg \& Haerdi, 1993). Two studies have shown that colorectal cancer cases have lower fecapentaene excretion than controls (Schiffman et al. 1989; De Kok et al. 1993) and synthetic fecapentaene-12 is not a rodent large bowel carcinogen (Ward et al. 1988; Weisburger et al. 1990). However, it is able to induce colonic proliferation (Hinzman et al. 1987) and is a promoter in tumours induced with $N$-methyl- $N$-nitrosourea (Zarkovic et al. 1993). There have been few studies of the effect of diet on fecapentaene excretion in humans although no relationship was detected in a questionnaire study with dietary fibre. High excreters were less likely to be consuming vitamins $\mathrm{C}$ and $\mathrm{E}$ (Schiffman, 1987).

\section{Bacterial deconjugation}

Conjugation with glucuronide is an important part of hepatic 'phase II' enzyme activity rendering foreign compounds more water-soluble for urine excretion and less likely to be absorbed after reaching the gut in bile. Other phase II enzymes form sulphate and glutathione conjugates. Deconjugation, however, is part of the metabolic role of the large bowel flora, but as a result reabsorption occurs and an enterohepatic circulation is established. This is important in bile acid and oestrogen metabolism, and $\beta$-glucuronidase activity may be relevant to the metabolism of some genotoxic compounds (see pp. 223-224) in human diets. In plants, most flavonoids and sulphur containing compounds (see pp. 224 226) are conjugated with sugars; deconjugation by bacterial glycosidase will release the parent molecule. Nitrate reductase activity is required for dissimilatory reduction of nitrate to nitrite and therefore NOC formation within the colon (see p. 222).

There is extensive evidence of the effect of dietary modification on rodent bacterial enzyme activity (Rowland, 1991). The relevance to human microflora is uncertain since for example caecal $\beta$-glucuronidase levels are reported as $156 \mu \mathrm{mol} / \mathrm{h}$ per $\mathrm{g}$ in rats, but lower 
in mice ( $43 \mu \mathrm{mol}$ ) and in human faeces, $36 \mu \mathrm{mol}$ (Rowland et al. 1986). $\beta$-Glucosidase and $\beta$-glucuronidase responses to dietary pectin are different in humans compared with rats and mice (Rowland \& Mallett, 1990). In human studies, Reddy et al. (1974) suggested that removal of meat from the diet reduced faecal $\beta$-glucuronidase levels, and Goldin et al. (1980) reported lower levels in vegetarians compared with omnivores. Johansson et al. (1990) and Ling \& Hänninen (1992) found a reduction in faecal levels when omnivores changed to a vegetarian or vegan diet. Total outputs are unlikely to be changed since faecal weight when reported is generally greater than that observed with high meat diets. None of these studies was highly controlled and differences could have arisen from a number of differences in diet, for example an increase in starch and NSP consumption.

Goldin et al. (1980) could not detect a significant change with a more direct trial in which either red meat was eliminated or a supplement of bran was given. However, supplements of $18 \mathrm{~g} / \mathrm{d}$ of pectin and $30 \mathrm{~g}$ bran halved $\beta$-glucuronidase activity in six volunteers (Mallett et al. 1988 a). In rats with an introduced human faecal flora, high fat human diets induced a significantly higher caecal $\beta$-glucuronidase activity (Rumney et al. 1992, 1993), but in humans Mallett et al. (1988a) found no effect of a supplement of fat, and Cummings et al. (1978) found no difference in a controlled study in which dietary fat was increased from 62 to $152 \mathrm{~g}$ per day. In humans therefore, any effect of diet on bacterial $\beta$-glucuronidase is likely to be brought about by fermentation of starch and NSP, rather than changes in fat intake. Kadlubar (1994) suggests that bacterial glucuronidase deconjugation, at least in relation to heterocyclic amines, is probably unimportant since there is little effect of bile duct ligation on DNA adduct formation (see p. 223) with heterocyclic amines in the colon and other tissues.

$\beta$-Glucosidase stimulation, liberating flavonoids and sulphur-containing compounds during fermentation from increased starch and NSP, might be important in humans but activity per $\mathrm{g}$ faeces was halved when $18 \mathrm{~g}$ pectin were fed and significantly reduced with $30 \mathrm{~g}$ bran per day (Mallett et al. 1988a). Johansson et al. (1990) found no change in glucosidase activity with a change to vegetarian diets. The importance of the effects of diet on $\beta$-glucosidase activity in humans remains to be established. Contrary to expectations, quercetin is better absorbed when conjugated as the glucoside than when not (Hollman et al. 1996).

Johansson et al. (1990) found reductions in arylsulphatase activity in individuals placed on vegetarian diets, but there have been no other investigations of the effect of diet in humans on bacterial arylsulphatase activity, nor of glutathione deconjugases. In animals, bran and fructooligosaccharides inhibit faecal nitrate reductase activity (Mallett et al. 1986; Rowland \& Tanaka, 1993), but there has been little investigation of the effect of diet on activity of this enzyme in humans.

\section{Sulphite}

Sulphite is a widely used preservative in foods such as jams, potato products and wines. Some water supplies have high sulphate levels and sulphur-containing amino acids in meat are major sources in western diets. On absorption into the blood stream, sulphite is oxidized to sulphate. Some sulphate then reaches the large bowel, where it acts as an electron acceptor for sulphate reducing bacteria, which are able to succeed in competition with methanogenic bacteria for hydrogen produced during fermentation. Western populations are therefore less frequent carriers of methanogens, and more frequent carriers of sulphate reducing bacteria than rural African populations (Gibson et al. 1988; Segal et al. 1988). The end product of the activities of sulphate reducing bacteria is hydrogen sulphide, which is highly toxic, inhibits butyrate oxidation, and which has had a role proposed for it in colitis and large bowel cancer (Roediger et al. 1993). 


\section{Nitrogen metabolism}

Approximately $2 \mathrm{~g}$ nitrogen, equivalent to $12 \mathrm{~g}$ protein, enter the large bowel daily, mainly in the form of protein, peptides and amino acids (Gibson et al. 1976; Chacko \& Cummings, 1988). The amount can be increased by increasing protein intake (Gibson et al. 1976; Silvester \& Cummings, 1995), by heat treatment of dietary proteins (Porter \& Rolls, 1971; Corpet et al. 1994), and by the physical form of food (Chacko \& Cummings, 1988). The proteins in pulses, for example, are poorly digested in the small gut when eaten whole, but $90 \%$ digested when homogenized before consumption (Chacko \& Cummings, 1988).

Many different types of proteolytic bacteria are found in the large gut; extracellular proteinases such as those of the clostridia are related to pathogenicity but intracellular or cell associated proteinases are likely to contribute to general proteolysis in the colon. $\mathrm{pH}$ optima are alkaline to neutral, and production varies according to species, probably in response to different fermentation conditions. Production may therefore respond to active carbohydrate fermentation in the right colon, but when readily fermented carbohydrates, such as pectin, are exhausted other proteolytic enzymes may respond to protein released from bacterial cell lysis in the left colon (Macfarlane \& Cummings, 1991).

Peptides are particularly important, having been shown to stimulate the growth of many intestinal bacteria. Uptake is rapid, and since there are no specific transport mechanisms in the colonic mucosa, unlike in the small bowel, significant host utilization is unlikely. Most bacteria are unable to obtain much energy from amino acid fermentation, but some are more versatile and deaminate to form ammonia, SCFA, and a variety of other products including phenols and branched chain fatty acids (Macfarlane \& Cummings, 1991). Phenols increase in urine in response to increase meat consumption (Cummings et al. 1979) and, as promoters, have been implicated in bowel cancer (Bone et al. 1976). However, there is no clear association epidemiologically between urinary phenol excretion and cancer incidence, and urinary phenol is probably a non-specific indicator of nitrogen fermentation in the gut (Bingham, 1988). When carbohydrate fermentation is active, ammonia is assimilated into glutamine or glutamate when the amino group can be distributed to other amino acids as required (Macfarlane \& Cummings, 1991).

\section{Ammonia}

When carbohydrate supplies are limited ammonia concentrations accumulate in vitro (Macfarlane et al. 1986) but in the presence of fermentable carbohydrate, ammonia is used for bacterial protein synthesis, and faecal ammonia concentration falls (Cummings et al. 1979). The finding in rodents that rapidly fermented high pectin diets induce higher levels of ammonia in the distal colon and lower levels in the caecum (Lupton \& Marchant, 1989) is to be expected, since carbohydrate fermentation in the distal colon will be exhausted at this site with a rapidly fermented carbohydrate such as pectin.

Ammonia in drinking water enhances cell proliferation at levels of 5-10 mmol found in the human colon, promotes $N$-methyl- $N^{\prime}$-nitro- $N$-nitrosoguanidine induced adenocarcinomas in rodents (Tsujii et al. 1992, 1993) and has been implicated in large bowel carcinogenesis (Visek, 1978). In humans, high meat or protein diets increased faecal ammonia concentration (from 10 to $30 \mathrm{mmol} / \mathrm{l}$ faecal dialysate) and greater starch and NSP intakes reduced it (Cummings et al. 1979; Bingham et al. 1996). There is no effect of unfermentable bran, nor of resistant starch (Silvester et al. 1995; Bingham et al. 1996). Altered faecal ammonia levels may therefore be important in promotion of carcinogenesis; patients with uterosigmoidostomies who have luminal ammonia concentrations as high as $100 \mathrm{~mm}$ have a greatly increased risk of developing tumours distal to the site of ureteric implantation (Tank et al. 1973; McConnell et al. 1979). 


\section{$N$-nitroso compounds}

Preformed NOC have not consistently been associated with large bowel cancer; oral doses of nitrosamines in animal feeding studies, for example, mainly result in liver and oesophageal tumours (Peto et al. 1984). Nitrosated amides are direct acting carcinogens, tending to cause tumours near to the site they are produced, whereas nitrosated amines require hydroxylation via cytochrome $\mathrm{P} 450$ enzymes and can initiate tumours at distal sites (Shuker, 1989). Nitrosamines are efficiently metabolized in the liver, little of an ingested dose of $N$-nitrosodimethylamine reaching the circulation (Bartsch \& Montesano, 1984). Preformed NOC occur in food but technological changes in the production of the major sources, beer and nitrite cured meat products, have halved dietary consumption of volatile nitrosamines to about $0.5 \mu \mathrm{g} / \mathrm{d}$ (Preussman, 1984). The major non-dietary exogenous source is tobacco, the mainstream smoke from one cigarette containing up to $65 \mu \mathrm{g}$ volatile nitrosamines and the side stream smoke $1000 \mu \mathrm{g}$ (Preussman, 1984).

Endogenous formation of NOC also occurs, since the colonic lumen is rich in amines and amides produced primarily by bacterial decarboxylation of amino acids. In the presence of a nitrosating agent, these can be $N$-nitrosated to a large variety of NOC. Several mechanisms are involved, and chemical $N$-nitrosation may occur at low $\mathrm{pH}$, under neutral or alkaline conditions (as in the small and large intestine), and be enhanced by the presence of various catalysts such as minerals, including iron, and formate. The nitrosating agents are nitric oxide ( $\mathrm{NO}^{*}$ ) for amides and $\mathrm{N}_{2} \mathrm{O}_{3}$ for amines, which is produced from nitrite at low $\mathrm{pH}$. At higher $\mathrm{pH}$, when nitrosation proceeds at a faster rate, $\mathrm{N}_{2} \mathrm{O}_{3}$ is also produced from nitric oxide (NO•) by reaction with molecular oxygen (Leaf et al. 1989). In the anaerobic large bowel, nitrate entering the body partly in food and water is reduced to nitrite in the colon during dissimilatory nitrate metabolism by the colonic flora. Supplements of nitrate have therefore been shown to elevate faecal NOC levels (Rowland et al. 1991). A number of facultative and anaerobic colonic bacteria are also able to catalyse the formation of NOC at an optimum pH of 7.5 (Suzuki \& Mitsuoka, 1984; Calmels et al. 1985).

There is another significant source of endogenous nitrate production, which has been deduced for some time, since nitrate excretion exceeds that consumed in food and water (Witter et al. 1979). Wagner et al. (1983) showed that nitrate synthesis is enhanced during immunostimulation, and Stuehr \& Marletta (1985) showed that nitrite and nitrate are produced from macrophages. Studies with ${ }^{15} \mathrm{~N}$ established that the source is dietary arginine, used to produce NO, which together with superoxide cause oxidative injury and cell death (Iyengar et al. 1987). Other fields of research established that NO accounted for the biological activity of endothelium-derived relaxing factor and inducible nitric oxide synthase produces continuous amounts of NO from arginine (Palmer et al. 1987; Änggård, 1994). Increased arginine from protein might be expected to increase urine nitrate excretion, an effect which has been shown in animals (Mallett et al. $1988 \mathrm{~b}$; Ward et al. 1989). Thus, NO from stimulated macrophages in the large bowel mucosa, together with nitrite produced from reduced nitrate diffusing into the gut, are therefore available for NOC formation.

In the 1980s it was established that faecal samples contain negligible amounts of volatile NOC (Archer et al. 1981), but since that time newer methods to measure total NOC by chemiluminescence have been developed. Rowland et al. in 1991 detected an average of $13 \mu \mathrm{g} /$ faecal sample on a low $(11 \mathrm{mg}$ ) nitrate diet and found a marked increase to $60 \mathrm{\mu g} / \mathrm{sample}$ with a $300 \mathrm{mg} / \mathrm{d}$ supplement of nitrate in humans. High protein diets have also been shown to increase urine $N$-nitrosoproline levels in animals (Mallett et al. 1988 b; Ward et al. 1989). In humans, a 3-4-fold increase in protein, as meat, has been 
shown to increase faecal NOC levels 4-fold (Silvester et al. 1995; Bingham et al. 1996). NOC are alkylators, and alkylative DNA adducts of $\mathrm{O}^{6}$ methylguanine have been detected in human colonic tissue (Hall et al. 1991). Very low levels are found, because the adduct is efficiently repaired (Margison \& O'Connor, 1990). Experiments with the direct acting carcinogen $N$-methyl- $N$-nitrosourea in rats, known to induce $\mathrm{G}$ to $\mathrm{A}$ transitions, have detected mutations in $\mathrm{K}$ ras in codons 12 and 13, but only in $30 \%$ carcinomas and $2 \%$ adenomas (Jacoby et al. 1992). 1,2-dimethylhydrazine, a carcinogen requiring activation, does induce a high percentage of $\mathrm{K}$ ras mutations in codons 12 and 13 of rat tumours (Jacoby et al. 1991). The effect of high meat diets in inducing alkylative mutations typical of NOC and relevant to colon cancer (see p. 201-202) is under active investigation in humans.

\section{Heterocyclic aromatic amines}

Over 20 mutagenic heterocyclic amines (HAA) have been isolated from cooked fish, beef, chicken, pork, soyabeans, and isolated proteins. All except one (Lys-P-1) isolated so far have an exocyclic amine (Eisenbrand \& Tang, 1993). The type of cooking, time, temperature, type and content of fat, all affect the amount and type of HAA found. Grilled or fried rare to medium rare meat contains less than well done meat; a standard protocol of grilling or frying for $6 \mathrm{~min}$ at $200^{\circ} \mathrm{C}$ surface temperature is generally used to produce experimental amounts. Mutagenicity can be reduced by deep frying and boiling, and increased in beef if butter rather than oil is used in cooking. Generally, frying, grilling and barbequeing generate more HAA than stewing, steaming, microwaving or poaching (Barrington et al. 1990; IFT, 1993; Layton et al. 1995). The mutagens are formed on the outside and pan residues contain significant amounts. They are formed probably from Maillard reactions between a hexose such as glucose and an amino acid with linkage of the resulting aldehyde with creatinine (Jagerstaad et al. 1986).

In rodents, heterocyclic amines are carcinogenic in a wide variety of organs, mainly liver but including skin, lung, and mammary gland. Three, MeIQ (2-amino-3,4-dimethylimidazo[4,5-f]quinoline), IQ (2-amino-3-methylimidazo[4,5-f]quinoline), and PhIP (2amino-1-methyl-6-phenylimidazo-[4,5-b]pyridine) are large bowel carcinogens (Takayama et al. 1984; Kato et al. 1989; Ito et al. 1991). PhIP, although relatively less mutagenic than other HAA, is as carcinogenic at the same levels of administration, $0.04 \%$ in rodent diets. It is also the most abundant in cooked food; beefsteak fried for $6 \mathrm{~min}$ at $190{ }^{\circ} \mathrm{C}$ for example contains $23.5 \mathrm{ng} / \mathrm{g} \mathrm{PhIP}$ and $5 \cdot 1 \mathrm{ng}$ MeIQx (Gross, 1990). Calculated daily intakes of total HAA range from 0.4 to $16 \mu \mathrm{g} / \mathrm{d}$ (Wakabayashi et al. 1992), but this is in the order of 1 to 1000 to 5000 less than that found to induce carcinogenicity (Sugimura, 1986). Maximum to minimum risks of between 1 to 1000 and 1 to 10000 have been calculated and these have been taken to suggest that HAA are relevant carcinogens in human cancer (Eisenbrand \& Tang, 1993). Comparisons between the amount required for carcinogenicity in animals and amounts found in diets therefore suggest that the relative contribution of HAA to colon cancer incidence may be small, for example $0 \cdot 25 \%$ of all colon cancers (Layton et al. 1995).

For conversion to the carcinogenic form, the exocyclic amine of IQ, PhIP and MeIQ is hydroxylated by cytochrome P450 enzymes (see p. 224-225), mainly CYP1A2. Covalent binding to deoxyguanosine in DNA then occurs. There are organ, species, and individual differences in P450 enzymes so that direct extrapolation from rodent experiments to human risks may be misleading. Comparatively high levels of $\mathrm{PhIP}$ adducts have been found in human colonic tissue (Friesen et al. 1994).

The large bowel flora and dietary NSP may also be important since in rats low fat, low beef, high NSP diets have been shown to enhance excretion of IQ sulphamate and sulphate metabolites, and to reduce irreversible binding of IQ to a surrogate of DNA, polyethyleneimine, compared with a high meat, high fat, low NSP diet (O'Neill et al. 1992). 
This suggests that these diets alter IQ metabolism so that more is detoxified and less is hydroxylated to the active metabolite. Bacteria are able to convert IQ to another metabolite, 7OH-IQ, and beef dripping and human high NSP diets have been shown in rats with human faecal flora to enhance this metabolism (Rumney et al. 1993). Weisburger et al. (1994) have shown that this metabolite is not carcinogenic in rodents, and it is possible that this is another detoxification metabolite whose excretion is enhanced by high NSP diets.

Owing partly to the comparatively small amounts of HAA found in human diets in comparison with the amount required for carcinogenicity, the importance of HAA in large bowel cancer is uncertain. The mutations established so far in colon cancer (see pp. 201-202) are mainly point mutations, of single bases, rather than the deletion or addition of a nucleotide, a frameshift. However, in mutagenicity tests, the HAA tend to produce frameshifts rather than transitions (Hatch et al. 1988). No obvious mutations in ras or $\mathrm{p} 53$ have been shown in colon cancers induced in rats by PhIP or IQ (Weisburger, 1993). Nevertheless, PhIP has attracted particular attention because it tends to be the most abundant, and colon tumours that are produced from it in rats have a high frequency of microsatellite instability which is similar to that seen in human inherited and sporadic colorectal cancers (see pp. 201-202) (Canzian et al. 1994).

\section{SYSTEMIC FACTORS}

n-3 and n-6 fatty acids

Animal studies have indicated a reduction in colon cancer incidence with increased levels of fish oils (see pp. 217-218), reduced cell proliferation (Steinbach et al. 1993), and reduced aberrant crypt formation (Takahashi et al. 1993). The polyunsaturated $\omega 3$ and $\omega 6$ fatty acids are metabolized to a range of compounds that have many physiological activities at very low concentrations, including an inflammatory response. Arachidonic acid $(\omega 6)$ is metabolized to leukotriene B4 which is more inflammatory than leukotriene B5 metabolized from eicosapentaenoic acid ( $\omega 3$ ) in fish oils (Leaf \& Weber, 1988). Two studies in humans have also indicated reduced rectal cell proliferation rates with supplements of fish oils, one in volunteers and one in patients with polyps. In the patients with polyps, a placebo of olive oil was used, and the difference occurred in the upper crypt compartments associated with higher risk of adenomas, whilst in the volunteers there was a general reduction (Anti $e t$ al. 1992; Bartram et al. 1993). Prostaglandin E2, another inflammatory prostaglandin produced from arachidonic acid, was also reduced (Bartram et al. 1993). Low doses of fish oils are as effective as high doses (Anti et al. 1994). Non-steroidal anti-inflammation drugs such as piroxicam, indomethicin and aspirin also inhibit prostaglandin and chemically induced large bowel tumours (Reddy et al. 1990, 1993). In humans, several studies show that use of aspirin is associated with reduced risk of colorectal cancer (Marnett, 1992).

\section{Effects of diet on Phase I and II enzyme activity}

Drugs and other xenobiotics are known to be metabolized by a variety of enzyme catalysed reactions. These have been classified into phase I and phase II reactions: phase I reactions (oxidation, hydroxylation, reduction, hydrolysis) generally render compounds more reactive, whereas phase II (conjugations) generally, but not exclusively, decrease biological activity and water solubility, hence facilitating their excretion (Williams, 1978). In human large bowel cancer, these enzyme activities could have a role.

Heterocyclic amines and $N$-nitrosamines are activated by hydroxylation (phase I) by P450 enzymes present in the liver and small intestinal mucosa. The P450 enzyme CYP1A2, which $N$-oxidizes aromatic amines, also catalyses the demethylation of caffeine, and 
caffeine is also acetylated before excretion in urine. Using a standard dose of caffeine as a surrogate to phenotype individuals into fast or slow oxidizers, patients with large bowel cancer have been shown to be faster oxidizers and acetylators than healthy matched controls (Kadlubar et al. 1992). However, genotyping of the polymorphic $N$-acetyltransferase 2 in colonic tissue does not show a difference between cases and controls and it is suggested that aromatic amine acetylation in the colon is largely determined by NAT1, which is monomorphic and does not segregate individuals into fast and slow acetylators (Rodriguez et al. 1993). Phenotypic studies of cases and controls in large bowel cancer have not been controlled for diet, and a large number of dietary variables are known to affect hepatic and gastrointestinal phase I and II enzyme activity, mainly in animals and to a limited extent in humans.

Acetylation (phase II) also occurs in activation of PhIP. Acetylation of PhIP occurs in the colon, but not in liver (Turesky et al. 1991). The phase II enzyme glutathione S-transferase(u) may be also important, because a greater number of glutathione S-transferase(u) null compared with competent patients have been found amongst cases of colorectal cancer than in healthy matched controls (Strange et al. 1991).

\section{Nutrients}

There is an extensive literature showing that most P450 enzyme system activity is decreased when protein intake is reduced, probably because protein synthesis and liver cell proliferation are retarded (see Yang \& Yoo, 1991). Hayes et al. (1978) found that changes occurred within 1-2 weeks of a change in protein intake in rats. Phase II enzyme activity may also be reduced, so that the net result may be an increase or decrease in toxicity of xenobiotics in protein deficient animals (Yang \& Yoo, 1991). Both the total amount and type of fat seem to be important in maintaining hepatic high levels of P450, although at levels of $10-20 \%$ by weight saturates and monounsaturates seem to be less effective than polyunsaturates (Yang \& Yoo, 1991). In the small intestine there seems to be little effect of fat, but high corn oil diets increase P450 enzymes in rat colon microsomes with little effect in germ free rats (Noordhoek \& van Bladeren, 1991). Phase II enzyme activity may also be decreased, for example glutathione transferase activity arising from a deficiency of cysteine, so that toxicity of pesticides in animals may be further increased (Yang \& Yoo, 1991).

In rodents, riboflavin is essential for flavoenzymes in P450 enzymes, and deficiency causes marked reductions in activity in both the liver and intestine (Yang \& Yoo, 1991; Noordhoek \& van Bladeren, 1991). Iron deficiency seems to increase hepatic activity but decrease small intestinal hydroxylase, an effect which requires intraluminal supplies to return to normal levels as epithelial cells migrate from the crypts to tips of the mucosal villi (Hoensch et al. 1976). Deficiencies of vitamins A and E also alter P450 enzyme activity.

These effects in animals are likely to account for some of the known effects of nutrients on carcinogenesis in animal models (see pp. 214-216). However, to what extent it is possible to extrapolate to human cancer is unknown, for example in the metabolism of HAA, since there has been little investigation of the effect of nutrients in humans. A change from a $40 \%$ to $10 \%$ protein diet decreased theophylline clearance, and semisynthetic diets also reduce small intestinal P450 monooxygenase activity in humans (Anderson et al. 1982; Hoensch et al. 1984).

\section{Vegetables}

Using animal models, Wattenberg (1971) was the first to show that vegetable constituents such as indole-3-carbinol have a profound effect on intestinal P450 activity. On the basis of extensive evidence showing inhibition of carcinogenesis at a variety of sites (though not 
the large bowel) Wattenberg proposed a classification of the numerous constituents of fruits and vegetables, based on their ability to prevent carcinogenesis. Examples were vitamin $\mathrm{C}$, which inhibits $N$-nitrosamine formation, and blockers, for example phenols and isothiocyanates, which have effects on phase I and phase II enzyme activity (Wattenberg, 1985).

Indoles and isothiocyanates are derived from glucosinolates of which there are about 120 found in brassica vegetables such as broccoli, cabbage and Brussels sprouts (Fenwick et al. 1982). They may be either phase I or phase II enhancers, for example, and broccoli contains indoles, which have been shown to enhance hepatic and small intestinal phase I enzymes and to elevate large bowel tumour production (Loub et al. 1975; Pence et al. 1986). Sulphoraphane, identified in broccoli, has been shown to be an inducer of the phase II enzymes quinone reductase and glutathione S-transferase (Zhang et al. 1992). All of the above studies have been conducted in animals given large quantities of chemical carcinogens or in cell culture lines, and the applicability of these findings to human cancer and predictability at different organs is uncertain. Diallyl sulphide in garlic induces glutathione S-transferase and suppresses colon tumours induced by dimethylhydrazine, but in another model it enhances hepatocarcinogenesis. The related diallyl disulphide was, however, an inhibitor of colon carcinogenesis (Wargovich, 1987; Sparnins et al. 1988; Takahashi et al. 1992). Furthermore, the effect of these compounds on hepatic phase I and II enzyme activity may not predict their effect in the large bowel mucosa which may be more relevant to colon cancer (O'Neill et al. 1996).

Nevertheless, genotypes who are glutathione S-transferase null are at increased risk of colon cancer (Strange et al. 1991). Large quantities of Brussels sprouts (3 portions per day) have been found to elevate liver glutathione S-transferase activity in humans and to reduce oxidative DNA damage (Bogaards et al. 1994; Nijhoff et al. 1995; Verhagen et al. 1995). There is much current interest in constituents of vegetables and fruit that can act as chemopreventers, particularly in those which induce phase II enzymes, but not phase I (Talalay et al. 1991).

\section{Folate}

Vegetables are a major source of folate in human diets and folate, vitamin $\mathbf{B}_{12}$, methionine and choline are critical elements in methyl group metabolism and therefore in DNA metabolism and replication. There is some epidemiological support for a role for DNA hypomethylation in increasing risk of colon cancer, although not from diet (see pp. 212-213). In an animal model of colon cancer, rats fed folate deficient diets had a greater incidence of dysplasia and carcinoma and significantly fewer of them were free from neoplastic lesions than the control animals (Cravo et al. 1992). In a small supplementation study of patients with resected neoplasms, rectal DNA methylation increased with folate (Cravo et al. 1994). However, the importance of folate and hypomethylation is uncertain since intestinal neoplasia has been found to be suppressed by DNA hypomethylation in a DNA methyltransferase deficient mouse, and folate depletion did not reduce colonic DNA methylation in rats (Laird et al. 1995; Kim et al. 1995).

\section{Flavonoids}

A very large class of natural compounds, widespread in plants, mainly as the glycosides, is the flavonoids. They participate in photosynthesis and they and their breakdown products are yellow and orange pigments and, as anthocyanins, blue and red pigments. At least $1 \mathrm{~g}$ per day of flavonoids are present in human food, and tea and wine contain large quantities. In the 1920 s they were classified by Szent-Györgyi as 'Vitamin P' since they were found to cure the haemorrhagic symptoms of scurvy (Havsteen, 1983; Roger, 1988). 
The flavonoids have strong antioxidant properties, as they are metal ion chelators, scavengers of superoxide and $\mathrm{OH}$, and able to terminate lipid peroxidation chain reactions (Yang \& Wang, 1993). Early reports suggested that they would enhance phase I enzyme activity (IFT, 1993). Rutin and quercetin have been known for some time to be mutagenic, but more recent studies suggest them to be protective experimentally. However, although these compounds appear to have a protective effect in epidemiological studies of cardiovascular disease, no effects have been observed in one prospective study of cancer (Hertog et al. 1993; Goldbohm et al. 1996; Keli et al. 1996).

Green tea, and to a lesser extent black tea, contain flavonols such as epigallocatechin which are also part of the flavonoid group. Tea polyphenols increase phase II enzymes and inhibit phase I enzymes (Khan et al. 1992; Mukhtar et al. 1992). Deschner et al. (1991, 1993) have also found them to inhibit hyperproliferation, colonic abnormalities and tumour incidence in mice, regardless of the level of fat in the diet. Green tea has been consistently shown to inhibit carcinogenesis in the lung, oesophagus, forestomach, liver, duodenal and small intestine, in addition to the large bowel (Yang \& Wang, 1993). One of four rodent studies demonstrated no inhibition of colon carcinogenesis by green tea, but in mice green tea extracts significantly inhibited dimethylhydrazine-induced intestinal (mainly colon) cancer, as did epigallocatechin-3-gallate (Yin et al. 1994). Low doses per rat of green tea extracts $(0.05,0.01$, or $0.002 \%$ in drinking water) also inhibited $N$-methyl- $N$ nitrosourea induced colon carcinogenesis (Narisawa \& Fukaura, 1993). Oral postinitiation doses in rats of $0.01 \%$ green polyphenol extracts reduced azoxymethane tumour numbers by $60 \%$ and tumour incidence by $51 \%$, with a greater inhibition (53 and $38 \%$ respectively) at a higher, $0 \cdot 1 \%$, dose (Yamane et al. 1991). The effect of black tea, which is more commonly consumed by humans in western societies, has not been investigated so intensively for chemoprevention in bowel cancer, but limited studies suggest that it may have a similar effect. However, there is inconclusive epidemiological support for a role for either green or black tea drinking in large bowel cancer protection (Yang \& Wang, 1993; Goldbohm et al. 1996).

Other flavonoids, the isoflavones, inhibit models of breast cancer and have also been suggested to be important in the genesis of bowel cancer (Barnes et al. 1990; Setchell \& Adlercreutz, 1988). There is an extensive literature showing that one, genistein, inhibits NO synthase activity in vitro, but effects in vivo in relation to endogenous NOC formation (see pp. 222-223) have not been investigated.

\section{SUMMARY AND CONCLUSIONS}

Cross-sectional comparisons, case-control studies and trends in food intakes show high rates of colorectal cancer in populations consuming diets high in meat and fat, and low in starch, NSP and vegetables. These studies suggest that the potential for prevention of colorectal cancer by diet is very great. Attributable population risk estimates from casecontrol studies suggest that $25-35 \%$ of colorectal cancers might be prevented by high intake of vegetables and fibre and that $15-25 \%$ of colorectal cancers could be attributed to a high fat intake (Tomatis et al. 1990). There are plausible physiological reasons for a protective effect of starch and NSP in large bowel cancer. Cross-sectional comparisons suggest that the recommendation (Department of Health, 1991) to increase starch and NSP consumption in the UK by $50 \%$ from 12 to $18 \mathrm{~g} / \mathrm{d}$ will increase stool weight by $25 \%$ and reduce large bowel cancer incidence on a opulation level by $15 \%$.

Existing results from cohort investigations show only weak associations and more data are required from large studies using accurate dietary assessment techniques in populations where there is extensive dietary variation, and which have collected biological samples in 
order that interaction between diet, biomarkers of diet, and different genotypes that may determine risk can be examined. A major problem in epidemiological studies of large bowel cancer is the absence of an easily accessible intermediate risk marker, known to alter in response to diet in metabolic studies, that can be used to link dietary intake and the presence of the disease in either intervention or prospective studies.

To meet the Department of Health (1991) recommendations for NSP intake, vegetable and fruit consumption needs to double in the UK. Vegetables may have added benefits in reducing colorectal cancer rates because they contain antioxidant nutrients and flavonoids, sulphur-containing compounds, and folate, all of which can be shown to favourably affect factors thought to be important in reducing risk. Intervention studies are generally held to be the most robust way of testing hypotheses but those already conducted with $\beta$-carotene and vitamin $E$ have not reduced risk of either large bowel cancer or recurrence of precursor lesions such as adenomatous polyps. Results from other interventions with calcium, NSP and resistant starch are awaited.

A protective effect of starch and NSP probably arises from their marked effect on bacterial metabolism in the large bowel, which leads to an increase in stool weight, and in butyrate production, and reduced $\mathrm{pH}$, and levels of secondary bile acids, diacylglycerol, and free ammonia. In rodents given known carcinogens, 'insoluble' sources of NSP are generally protective, and high fat (or energy) diets increase tumorigenesis. Tumorigenesis may be reduced by $n-3$ fatty acids, but the effects of fat in rodent models of colon cancer are less consistent than those found in mammary tumorigenesis. In humans, a role for fat in increasing risk via increased bile acid excretion has been proposed. A risk from red and processed meat seems to be emerging from prospective studies, and high levels of meat increase faecal ammonia and NOC concentrations, and intakes of HAA. Some NOC and HAA are known carcinogens and some of the chromosomal mutations found in colorectal cancer are consistent with effects of NOC and HAA. Meat consumption should not increase. There has also been some interest in the past in the effect of bacterial enzymes in modifying carcinogen metabolism but the relevance of this to human diets and carcinogenesis is uncertain. The effect of diet on fecapentaene excretion is unknown. There are numerous different compounds in vegetables actively under investigation for their effect on carcinogenesis at different sites, including the large bowel, but intervention studies already conducted with $\beta$-carotene and vitamin $E$ suggest that the active ingredients in vegetables involved in colorectal cancer protection are not antioxidant nutrients. As these attempts to alter risk with supplements have so far not been successful, they are not recommended for the general population.

\section{REFERENCES}

ATBC (Alpha Tocopherol, Beta Carotene Cancer Prevention Study Group) (1994). The effect of vitamin E and $\beta$-carotene on the incidence of lung cancer and other cancers in male smokers. New England Journal of Medicine 330, $1029-1035$.

Anderson, K. E., Conney, A. H. \& Kappas, A. (1982). Nutritional influences on chemical biotransformations in humans. Nutrition Reviews 40, 16I-171.

Änggård, E. (1994). Nitric oxide: mediator, murderer, and medicine. Lancet 343, 1199-1206.

Anti, M., Armelao, F., Marra, G., Percesepe, A., Bartoli, G. M., Palozza, P., Parrella, P., Canetta, C., Gentiloni, N., DeVitis, I. \& Gasbarrini, G. (1994). Effect of different levels of $\omega 3$ fatty acids on rectal cell proliferation in patients at high risk for colorectal cancer. Gastroenterology 107, 1709-1718.

Anti, M., Marra, G., Armelao, F., Bartoli, G. M., Ficarelli, R., Percesepe, A., de Vitis, 1., Maria, G., Sofo, L., Rapaccini, G. L. et al. (1992). Effects of $\omega 3$ fatty acids on rectal mucosal proliferation in subjects at risk for colon cancer. Gastroenterology 103, 883-889.

Archer, M. C., Saul, R. L., Lyang-Ja Lee \& Bruce, W. B. (1981). Analysis of nitrate, nitrite and nitrosamines in human faeces. In Banbury Report 7. Gastrointestinal Cancer, pp. 321-327 [W. R. Bruce, P. Correa, M. Lipkin, S. Tannenbaum and T. D. Wilkins, editors]. New York: Cold Spring Harbor. 
Armstrong, B. \& Doll, R. (1975). Environmental factors and the incidence and mortality from cancer in different countries with special reference to dietary practices. International Journal of Cancer 15, 617-631.

Barnes, S., Grubbs, C., Setchell, K. D. R. \& Carlson, J. (1990). Soybeans inhibit mammary tumors in models of breast cancer. In Mutagens and Carcinogens in the Diet (Progress in Clinical \& Biological Research), pp. 239-253 [M. W. Pariza, H. U. Aeschbacher, J. S. Felton and S. Sato, editors]. New York: Wiley Liss.

Barrington, P. J., Baker, R. S. U., Truswell, A. S., Bonin, A. M., Ryan, A. J. \& Paulin, A. P. (1990). Mutagenicity of basic fractions derived from lamb and beef cooked by common household methods. Food and Chemical Toxicology 28, 141-146.

Bartram, H. P., Gostner, A., Scheppach, W., Reddy, B. S., Rao, C. V., Dusel, G., Richter, F. \& Kasper, H. (1993). Effects of fish oil on rectal cell proliferation, mucosal fatty acids and prostaglandin E2 release in healthy subjects. Gastroenterology 105, 1317-1322.

Bartsch, H. \& Montesano, R. (1984). Relevance of nitrosamines to human cancer. Carcinogenesis 5, 1381-1393.

Benito, E., Cabeza, E., Moreno, V., Obrador, A. \& Bosch, F. X. (1993). Diet and colorectal adenomas: a casecontrol study in Majorca. International Journal of Cancer 55, 213-219.

Bingham, S. A. (1988). Meat, starch and nonstarch polysaccharides and large bowel cancer. American Journal of Clinical Nutrition 48, 762-767.

Bingham, S. A. (1990 a). Mechanisms and experimental epidemiological evidence relating dietary fibre (non-starch polysaccharides) and starch to protection against large bowel cancer. Proceedings of the Nutrition Society 49, 153-171.

Bingham, S. A. (1990b). Diet and large bowel cancer. Journal of the Royal Society of Medicine 83, 420 422.

Bingham, S. A. \& Cummings, J. H. (1989). Effect of exercise and physical fitness on large intestinal function. Gastroenterology $97,1389-1399$.

Bingham, S. A., Pignatelli, B., Pollock, J., Ellul, A., Mallaveille, C., Gross, G., Runswick, S., Cummings, J. H. \& O'Neill, I. K. (1996). Does increased formation of endogenous $\mathrm{N}$ nitroso compounds in the human colon explain the association between red meat and colon cancer? Carcinogenesis 17, 515-523.

Bingham, S. A., Williams, D. R. R., Cole, T. J. \& James, W. P. T. (1979). Dietary fibre and regional large bowel cancer mortality in Britain. British Journal of Cancer 40, 456-463.

Bingham, S. A., Williams, D. R. R. \& Cummings, J. H. (1985). Dietary fibre consumption in Britain: new estimates and their relation to large bowel cancer mortality. British Journal of Cancer 52, 399-402.

Bodmer, W. F., Bailey, C. J., Bodmer, J., Bussey, H. J. R., Ellis, A., Gorman, R., Lucibello, C. F., Murday, V. A., Rider, S. H., Scambler, P., Sheer, D., Solomon, E. \& Spurr, N. K. (1987). Localisation of the gene for familial adenomatous polyposis on chromosome 5. Nature 328, 614-616.

Boffa, L. C., Lupton, J. R., Mariani, M. R., Ceppi, M., Newmark, H. L., Scalmati, A. \& Lipkin, M. (1992). Modulation of colonic epithelial cell proliferation, histone acetylation, and luminal short chain fatty acids by variation of dietary fiber (wheat bran) in rats. Cancer Research 52, 5906-5912.

Bogaards, J. J. P., Verhagen, H., Willems, M. I., van Poppel, G. \& van Bladeren, P. J. (1994). Consumption of Brussels sprouts results in elevated $\alpha$-class glutathione S-transferase levels in human blood plasma. Carcinogenesis 15, 1073-1075.

Boing, L., Martinez, R., Beyme, F. R. \& Oltersdorf, F. U. (1985). Regional nutritional patterns and cancer mortality in the Federal Republic of Germany. Nutrition and Cancer 7, 121-130.

Bone, E., Tamm, A. \& Hill, M. (1976). The production of urinary phenols by gut bacteria and their possible role in the causation of large bowel cancer. American Journal of Clinical Nutrition 29, 1448-1454.

Bos, J. L. (1989). ras Oncogenes in human cancer: a review. Cancer Research 49, 4682-4689.

Bostick, R. M., Fosdick, L., Wood, J. R., Grambsch, P., Grandits, G. A., Lillemoe, T. J., Louis, T. A. \& Potter, J. D. (1995). Calcium and colorectal epithelial cell proliferation in sporadic adenoma patients: a randomized, double-blinded, placebo-controlled clinical trial. Journal of the National Cancer Institute 87, 1307-1315.

Bostick, R. M., Potter, J. D., Kushi, L. H., Sellers, T. A., Steinmetz, K. A., McKenzie, D. R., Gapstyr, S. M. \& Folsom, A. R. (1994). Sugar, meat, and fat intake and non-dietary risk factors for colon cancer incidence in Iowa women. Cancer Causes and Control 5, 38-52.

Bostick, R. M., Potter, J. D., Sellers, T. A., McKenzie, D. R., Kushi, L. H. \& Folsom, A. R. (1993). Relation of calcium, vitamin $\mathrm{D}$, and dairy food intake to incidence of colon cancer among older women - the Iowa Women's Health study. American Journal of Epidemiology 137, 1302-1317.

Boyle, P., Kevi, R., Lucchuni, F. \& La Vecchia, C. (1993). Trends in diet-related cancers in Japan: a conundrum? Lancet 342, 752.

Bronner, C. E., Baker, S. M., Morrison, P. T., Warren, G., Smith, L. G., Lescoe, M. K., Kane, M., Earabino, Lipford, J., Lindblom, A. et al. (1994). Mutation in the DNA mismatch repair gene homologue hMLH1 is associated with hereditary non-polyposis colon cancer. Nature 368, 258-261.

Burkitt, D. P. (1969). Related disease-related cause? Lancet ii, 1229-1231.

Butterworth, C. E., Hatch, K. D., Gore, H., Mueller, H. \& Krumdieck, C. L. (1982). Improvement in cervical dysplasia associated with folic acid therapy in users of oral contraceptives. American Journal of Clinical Nutrition 35, 73-82.

Caderni, G., Bianchini, F., Dolora, P. \& Kriebel, D. (1989). Proliferative activity in the colon of the mouse and its modulation by dietary starch, fat, and cellulose. Cancer Research 49, 1655-1659. 
Calmels, S., Ohshima, H., Vincent, P., Gounot, A.-M. \& Bartsch, H. (1985). Screening of microorganisms for nitrosation catalysis at $\mathrm{pH} 7$ and kinetic studies on nitrosamine formation from secondary amines by $E$. col $i$ strains. Carcinogenesis 6, 911-915.

Canzian, F., Ushijama, T., Serikawa, T., Wakabayashi, K., Sugimura, T. \& Nagao, M. (1994). Instability of microsatellites in rat colon tumours induced by HAA. Cancer Research 54, 6315-6317.

Cassidy, A., Bingham, S. A. \& Cummings, J. H. (1994). Starch intake and colorectal cancer risk: an international comparison. British Journal of Cancer 69, 937-942.

Chacko, A. \& Cummings, J. H. (1988). Nitrogen losses from the human small bowel: obligatory losses and the effect of physical form of food. Gut 29, 809-815.

Clinton, S. K., Destree, R. J., Anderson, C. R., Truex, P. B., Imrey, P. B. \& Visek, W. J. (1979). DMH induced intestinal cancer in rats fed beef or soy bean protein. Nutrition Reports International 20, 335-342.

Clinton, S. K., Imrey, P. B., Mangian, H. J., Nandkumar, S. \& Visek, W. J. (1992). The combined effects of dietary fat, protein and energy intake on azoxymethane-induced intestinal and renal carcinogenesis. Cancer Research 52, 857-865.

Corpet, D. E., Bellier, R., Petrowitsch, S. \& Vigouroux, Y. (1994). Digestion and fermentation of proteins in rats fed keratin, albumin, cooked casein and antibiotics. Reproduction, Nutrition, Development 34, 57-64.

Corpet, D. E., Stamp, D., Medline, A., Minkin, S., Archer, M. C. \& Bruce, W. R. (1990). Promotion of colonic microadenoma growth in mice and rats fed cooked sugar or cooked casein and fat. Cancer Research 53 , 6955-6958.

Cravo, M., Fidalgo, P., Pereira, A. D., Gouveia Oliveira, A., Chaves, P., Selhub, J., Mason, J. B., Mira, F. C. \& Leitao, C. N. I. (1994). DNA methylation as an intermediate biomarker in colorectal cancer: modulation by folic acid supplementation. European Journal of Cancer Prevention 3, 473-479.

Cravo, M. L., Mason, J. B., Dayal, Y., Hutchinson, M., Smith, D., Selhub, J. \& Rosenberg, I. H. (1992). Folate deficiency enhances the development of colonic neoplasia in dimethylhydrazine-treated rats. Cancer Research 52, 5002-5006.

Cummings, J. H. (1981a). Dietary fibre and large bowel cancer. Proceedings of the Nutrition Society 40, 7-14.

Cummings, J. H. (1981 b). Short chain fatty acids in the human colon. Gut 22, 763-779.

Cummings, J. H., Bingham, S. A., Heaton, K. W. \& Eastwood, M. A. (1992). Fecal weight, colon cancer risk, and dietary intake of nonstarch polysaccharides (dietary fiber). Gastroenterology 103, 1783-1789.

Cummings, J. H., Hill, M. J., Bone, E. S., Branch, W. J. \& Jenkins, D. J. A. (1979). The effect of meat protein and dietary fiber on colonic function and metabolism. II. Bacterial metabolites in faeces and urine. American Journal of Clinical Nutrition 32, 2094-2101.

Cummings, J. H., Pomare, E. W., Branch, W. J., Naylor, C. P. E. \& Macfarlane, G. T. (1987). Short chain fatty acids in human large intestine, portal, hepatic and venous blood. Gut 28, 1221-1227.

Cummings, J. H., Stephen, A. M. \& Branch, W. J. (1981). Implications of dietary fibre breakdown in the human colon. In Banbury Report 7: Gastrointestinal Cancer, pp. 71-81 [W. R. Bruce, P. Correa, M. Lipkin, S. Tannenbaum and T. D. Wilkins, editors]. New York: Cold Spring Harbor.

Cummings, J. H., Wiggins, H. S., Jenkins, D. J. A., Houston, H., Jivraj, T., Drasar, B. S. \& Hill, M. J. (1978). Influence of diets high and low in animal fat on bowel habit, gastrointestinal transit time, fecal microflora, bile acid and fat excretion. Journal of Clinical Investigation 61, 953-963.

Decosse, J. J., Miller, H. H. \& Lesser, M. L. (1989). Effect of wheat fibre and vitamins C and E on rectal polyps in patients with familial adenomatous polyposis. Journal of the National Cancer Institute 81, 1290-1297.

De Kok, T. M. C. M., Pachen, D., Van Iersel, M. L. P. S., Baeten, C. G. M. I., Engels, L. G. J. B., ten Hoor, F. \& Kleinjans, J. C. S. (1993). Case control study on fecapentaene excretion in adenomatous polyps in the colon and rectum. Journal of the National Cancer Institute 85, 1241-1244.

Department of Health (1991). Dietary Reference Values for Food Energy and Nutrients for the United Kingdom (Report on Health and Social Subjects no. 41). London: HMSO.

Deschner, E. E., Ruperto, J. F., Lupton, J. R. \& Newmark, H. L. (1990). Butyrate (tributyrin) does not enhance AOM-induced colon tumorigenesis. Cancer Letters 52, 79-82.

Deschner, E. E., Ruperto, J., Wong, G. \& Newmark, H. L. (1991). Quercetin and rutin as inhibitors of azoxymethanol-induced colonic neoplasia. Carcinogenesis 12, 1193-1196.

Deschner, E. E., Ruperto, J. F., Wong, G. Y. \& Newmark, H. L. (1993). The effect of dietary quercetin and rutin on AOM-induced acute colonic epithelial abnormalities in mice fed a high fat-diet. Nutrition and Cancer $\mathbf{2 0}$, 199-204.

Doll, R., Forman, D., La Vecchia, C. \& Woutersen, R. (1993). Alcoholic beverages and cancers of the digestive tract. In Health Issues Related to Alcohol Consumption, pp. 125-166 [P. M. Verschuren, editor]. Brussels: ILSI.

Drasar, B. S. \& Irving, D. (1973). Environmental factors and cancer of the colon and breast. British Journal of Cancer 27, 167-172.

Eisenbrand, G. \& Tang, W. (1993). Food borne heterocyclic amines. Chemistry, formation, occurrence and biological activities. A literature review. Toxicology 84, 1-82.

Englyst, H. N., Hay, S. \& Macfarlane, G. T. (1987). Polysaccharide breakdown by mixed populations of human faecal bacteria. FEMS Microbiology Ecology 45, 163-171.

Englyst, H. N., Kingman, S. M. \& Cummings, J. H. (1992). Classification and measurement of nutritionally important starch fractions. European Journal of Clinical Nutrition 46 (Suppl. 2), S33-S50. 
Fearon, E. R. \& Vogelstein, B. (1990). A genetic model for colorectal tumorigenesis. Review. Cell 61, $759-767$.

Feingold, S. M., Sugger, V. L. \& Mathisen, G. E. (1983). Normal indigenous intestinal flora. In Intestinal Flora in Health and Disease, pp. 3-31 [D. J. Hentges, editor]. New York: Academic Press.

Fenwick, G. R., Heaney, R. K. \& Mullin, W. J. (1982). Glucosinolates and their breakdown products in food and food plants. CRC Critical Reviews in Food Science and Nutrition 18, 123-201.

Freeman, H. J. (1986). Effects of differing concentrations of sodium butyrate in 1,2-dimethylhydrazine induced rat intestinal neoplasia. Gastroenterology 91, 596-602.

Frentzel-Beyme, R. \& Chang-Claude, J. (1994). Vegetarian diets and colon cancer - the German experience. American Journal of Clinical Nutrition 59, 1143S-1152S.

Friedenreich, C. M., Howe, G. R. \& Miller, A. B. (1991). The effect of recall bias on the association of calorie providing nutrients and breast cancer. Epidemiology 2, 424429.

Friedenreich, C. M., Slimani, N. \& Riboli, E. (1992). Measurement of past diet: review of previous and proposed methods. Epidemiologic Reviews 14, 177-196.

Friend, S. (1994). A glimpse at the puppet behind the shadow play. Science 265, 334-335

Friesen, M. D., Kaderlik, K., Lin, D. X., Garren, L., Bartsch, H., Lang, N. P. \& Kadlubar, F. F. (1994). Analysis of DNA adducts of 2-amino-1-methyl-6-phenylimidazo[4,5-b]pyridine in rat and human tissues by alkaline hydrolysis and gas chromatography electron capture mass spectrometry: validation by comparison with ${ }^{32} \mathrm{P}$ postlabelling. Chemical Research in Toxicology 7, 733-739.

Garg, M. L. \& Haerdi, J. C. (1993). The biosynthesis and functions of plasmalogens. Journal of Clinical Biochemistry and Nutrition 14, 71-82.

Garland, C. F., Comstock, G. W., Garland, F. C., Helsing, K. J., Shaw, E. K. \& Gorham, E. D. (1989). Serum 25-hydroxyvitamin D and colon cancer: eight-year prospective study. Lancet ii, 1176-1178.

Garland, C., Shekelle, R. B., Barrett-Connor, E., Criqui, M. H., Rossof, A. H. \& Paul, O. (1985). Dietary vitamin $\mathrm{D}$ and calcium and risk of colorectal cancer: a 19-year prospective study in men. Lancet $\mathbf{i}, 307-309$.

Gerhardsson de Verdier, M., Steineck, G., Hagman, U., Rieger, A. \& Norell, S. E. (1990). Physical activity and colon cancer: a case reference study in Stockholm. International Journal of Cancer 46, 985-989.

Gibson, G. R., Macfarlane, G. T. \& Cummings, J. H. (1988). Occurrence of sulphate-reducing bacteria in human faeces and the relationship of dissimilatory sulphate reduction to methanogenesis in the large gut. Journal of Applied Bacteriology 65, 103-111.

Gibson, J. A., Sladen, G. E. \& Dawson, A. M. (1976). Protein absorption and ammonia production: effects of dietary protein and removal of colon. British Journal of Nutrition 35, 61-65.

Giovannucci, E., Rimm, E. B., Stampfer, M. J., Colditz, G. A., Ascherio, A. \& Willett, W. C. (1994). Intake of fat, meat, and fiber in relation to risk of colon cancer in men. Cancer Research 54, 2390-2397.

Giovannucci, E., Stampfer, M. J., Colditz, G. A., Manson, J. E., Rosner, B. A., Longnecker, M., Speizer, F. E. \& Willett, W. C. (1993a). A comparison of prospective and retrospective assessments of diet in the study of breast cancer. American Journal of Epidemiology 137, 502-511.

Giovannucci, E., Stampfer, M. J., Colditz, G. A., Rimm, E. B., Trichopoulos, D., Rosner, B. A., Speizer, F. E. \& Willett, W. C. (1993 b). Folate, methionine, and alcohol intake and risk of colorectal adenoma. Journal of the National Cancer Institute 85, 875-884.

Giovannucci, E., Stampfer, M. J., Colditz, G., Rimm, E. B. \& Willett, W. C. (1992). Relationship of diet to risk of colorectal adenoma in men. Journal of the National Cancer Institute 84, 91-98.

Goldbohm, A., Hertog, M. G. L., Brants, H. A. M., van Poppel, G. \& van den Brandt, G. (1996). Consumption of black tea and cancer risk: a prospective cohort study. Journal of the National Cancer Institute 88, 93-100.

Goldbohm, R. A., van den Brandt, P. A., van't Veer, P., Brants, H. A. M., Dorant, E., Sturmans, F. \& Hermus, R. J. J. (1994). A prospective cohort study on the relation between meat consumption and the risk of colon cancer. Cancer Research 54, 718-723.

Goldin, B. R., Swenson, L., Dwyer, J., Sexton, M. \& Gorbach, S. L. (1980). Effects of diet and Lactobacillus acidophilus supplements on human fecal bacterial enzymes. Journal of the National Cancer Institute 64, $255-261$.

Graf, E. \& Eaton, J. W. (1993). Suppression of colonic cancer by dietary phytic acid. Nutrition and Cancer 19 , 11-19.

Greenberg, E. R., Baron, J. A., Tosteson, T. D., Freeman, D. H., Beck, G. J., Bond, J. H., Colacchio, T. A., Coller, J. A., Frankl, H. D., Haile, R. W. et al. (1994). A clinical trial of antioxidant vitamins to prevent colorectal adenoma. New England Journal of Medicine 331, 141-147.

Gross, G. A. (1990). Simple methods for quantifying mutagenic heterocyclic aromatic amines in food products. Carcinogenesis 11, 1597-1603.

Guillem, J. G., Obrian, C. A., Fitzer, C. J., Johnson, M. D., Forde, K. A., LoGerfo, P. \& Weinstein, B. (1987). Studies on protein kinase C and colon carcinogenesis. Archives of Surgery 122, 1475-1478.

Gupta, I., Suzuki, K., Bruce, W. R., Krepinski, J. J. \& Yates, P. (1984). A model study of fecapentaenes: mutagens of bacterial origin with alkylating properties. Science 225, 521-523.

Haenszel, W., Berg, J. W., Segi, M., Kurihara, M. \& Locke, F. B. (1973). Large-bowel cancer in Hawaiian Japanese. Journal of the National Cancer Institute 51, 1765-1779.

Hague, A., Manning, A. M., Hanlon, K. A., Huschtscha, L. I., Hart, D. \& Paraskeva, C. (1993). Sodium butyrate induces apoptosis in human colonic tumour cell lines in a p53-independent pathway. Implications for the possible role of dietary fibre in the prevention of large-bowel cancer. International Journal of Cancer $\mathbf{5 5}$, 498-505. 
Hall, C. N., Badawi, A. F., O'Connor, P. J. \& Safthill, R. (1991). The detection of alkylation damage in the DNA of human gastrointestinal tissues. British Journal of Cancer 64, 59-63.

Harris, C. C. (1993). p53 at the crossroads of molecular carcinogenesis and risk assessment. Science 262, 1980-1981.

Hatch, F. T., Felton, J. S. \& Knize, M. G. (1988). Mutagens formed in foods during cooking. ISI atlas of science. Pharmacology 36, 222-228.

Havsteen, B. (1983). Flavonoids, a class of natural products of high pharmacological potency. Biochemical Pharmacology 32, 1141-1148.

Hayes, J. R., Mgbodile, M. U. K., Merrill, A. H., Nerurkar, L. S. \& Campbell, T. C. (1978). The effect of dietary protein depletion and repletion on rat hepatic mixed function oxidase activities. Journal of Nutrition 108, 1788-1797.

Heilbrun, L. K., Nomura, A., Hankin, J. H. \& Stemmermann, G. N. (1989). Diet and colorectal cancer with special reference to fiber intake. International Journal of Cancer 44, $1-6$.

Heimburger, D. C., Alexander, C. B., Birch, R., Butterworth, C. C., Bailey, W. C. \& Krumdieck, C. L. (1988). Improvement in bronchial squamous metaplasia in smokers treated with folate and vitamin $\mathrm{B}_{12}$. Journal of the American Medical Association 259, 1525-1530.

Hertog, M. G. L., Feskens, E. J. M., Hollman, P. C. H., Katan, M. B. \& Kromhout, D. (1993). Dietary antioxidant flavonoids and risk of coronary heart disease - the Zutphen Elderly study. Lancet 343, $1007-1011$.

Higginson, J. \& Oettle, A. G. (1960). Cancer incidence in the Bantu and Cape coloured race of South Africa. Journal of the National Cancer Institute 24, 584-671.

Hinzman, M. J., Novotny, C., Ullah, A. \& Shamsuddin, A. M. (1987). Fecal mutagen fecapentaene-12 damages mammalian colon epithelial DNA. Carcinogenesis 8, 1475-1479.

Hirayama, T. (1981). A large scale cohort study on the relationship between diet and selected cancer of digestive organs. In Banbury Report 7: Gastrointestinal Cancer, pp. 409-429 [W. R. Bruce, P. Correa, M. Lipkin, S. Tannenbaum and T. D. Wilkins, editors]. New York: Cold Spring Harbor.

Hoensch, H. P., Steinhardt, H. J., Weiss, G., Haug, D., Maier, A. \& Malchow, H. (1984). Effects of semisynthetic diets on xenobiotic enzyme metabolizing activity and morphology of small intestinal morphology of humans. Gastroenterology 86, 1519-1530.

Hoensch, H., Woo, C. H., Raffin, S. B. \& Schmid, R. (1976). Oxidative metabolism of foreign compounds in rat small intestine: cellular localization and dependence on dietary iron. Gastroenterology 70, 1063-1070.

Hoff, G., Moen, I. E., Trygg, K., Frølich, W., Sauar, J., Vatn, M., Gjone, E. \& Larsen, S. (1986). Epidemiology of polyps in the rectum and sigmoid colon. Evaluation of nutritional factors. Scandinavian Journal of Gastroenterology 21, 199-204.

Hollman, P. C. H., de Vries, J. H. M., van Leeuwen, S. D., Mengelers, M. J. B. \& Katan, M. B. (1996). Absorption of dietary quercetin glycosides and quercetin in healthy ileostomy volunteers. American Journal of Clinical Nutrition 62, 1276-1282.

Hollstein, M., Sidransky, D., Vogelstein, B. \& Harris, C. C. (1991). p53 mutations in human cancer. Science 253, $49-53$.

Howell, M. A. (1975). Diet as an etiological factor in the development of cancers of the colon and rectum. Journal of Chronic Diseases 28, 67-80.

IARC (International Agency for Research on Cancer) (1982). Large Bowel Cancer Group. Second international collaborative study on diet and cancer in Denmark and Finland. Nutrition and Cancer 4, 3-79.

IARC (1988). Alcohol Drinking (IARC Monographs no. 44). Lyon: International Agency for Research on Cancer.

IFT (Institute of Food Technologists) (1993). Potential mechanisms for food-related carcinogens and anticarcinogens. Food Technology 47(2), 105-118.

Ito, N., Hasegawa, R., Sano, M., Tamano, S., Esumi, H., Takayama, S. \& Sugimura, T. (1991). A new colon and mammary carcinogen in cooked food, 2-amino-1-methyl-6-phenylimidazo[4,5-b]pyridine (PhIP). Carcinogenesis $12,1503-1506$.

Iyengar, R., Stuehr, D. J. \& Marletta, M. A. (1987). Macrophage synthesis of nitrite, nitrate, and $N$-nitrosamines: precursors and role of the respiratory burst. Proceedings of the National Academy of Sciences, USA 84, $6369-6373$.

Jacobs, L. R. (1990). Influence of soluble fibres on experimental colon carcinogenesis. In Dietary Fibre, pp. 389-420 [D. Kritchevsky, C. Bonfield and J. W. Anderson, editors]. New York: Plenum Press.

Jacoby, R. F., Alexander, R. J., Raicht, R. F. \& Brasitus, T. A. (1992). K-ras oncogene mutations in rat colon tumours induced by $N$-methyl- $N$-nitrosourea. Carcinogenesis $13,45-49$.

Jacoby, R. F., Llor, X., Teng, B.-B., Davidson, N. O. \& Brasitus, T. A. (1991). Mutations in the K-ras oncogene induced by 1,2-dimethylhydrazine in preneoplastic and neoplastic rat colonic mucosa. Journal of Clinical Investigation 87, 624-630.

Jagerstaad, M., Reuterswaerd, A. L., Grivas, S., Olsson, K., Negishi, C. \& Sato, S. (1986). Effect of meat composition and cooking conditions on the formation of MelQx and its derivatives. Proceedings of the International Symposium of Princ Takamatsu Cancer Research Fund 1985, pp. 87-96.

Johansson, G. K. (1990). Effects of a Shift from a Mixed Diet to a Lactovegetarian Diet. PhD Thesis, Karolinska Institute, Stockholm. 
Johansson, G. K., Ottova, L. \& Gustafsson, J. A. (1990). Shift from a mixed diet to a lactovegetarian diet: influence on some cancer associated intestinal bacterial enzyme activities. Nutrition and Cancer 14, $239-246$.

Kadlubah, F. F. (1994). Rethinking the role of intestinal microflora in bioactivation of food-borne heterocyclic amine carcinogens. Journal of the National Cancer Institute 86, 5.

Kadlubar, F. F., Butler, M. A., Kaderlik, K. R., Chou, H. C. \& Lang, N. P. (1992). Polymorphisms for aromatic amine metabolism in humans. Relevance for human carcinogenesis. Environmental Health Perspectives 98, 69-74.

Kampman, E., Goldbohm, R. A., van den Brandt, P. A. \& van't Veer, P. (1994). Fermented dairy products, calcium, and colorectal cancer in the Netherlands Cohort Study. Cancer Research 54, 3186-3190.

Kato, T., Migita, H., Ohgaki, H., Sato, S., Takayama, S. \& Sugimura, T. (1989). Induction of tumors in the Zymbal gland, oral cavity, colon, skin and mammary gland of F344 rats by a mutagenic compound, 2-amino3,4-dimethylimidazo[4,5-f]quinoline. Carcinogenesis 10, 601-603.

Keli, S. O., Hertog, M. G. H., Feskens, J. M. \& Kroumhout, D. (1996). Dietary flavonoids, antioxidant vitamins and incidence of stroke. Archives of Internal Medicine 156, 637-642.

Khan, S. G., Katiyar, S. K., Agarwal, R. \& Mukhtar, H. (1992). Enhancement of antioxidant and phase II enzymes by oral feeding of green tea polyphenols in drinking water to SKH-1 hairless mice: possible role in cancer chemoprevention. Cancer Research 52, 4050-4052.

Kim, Y.-I., Christman, J. K., Fleet, J. C., Cravo, M. L., Salomon, R. N., Smith, D., Ordovas, J., Selhub, J. \& Mason, J. B. (1995). Moderate folate deficiency does not cause global hypomethylation of hepatic and colonic DNA or c-myc-specific hypomethylation of colonic DNA in rats. American Journal of Clinical Nutrition 61, $1083-1090$.

Kim, Y. S., Gum, J. R., Ho, S. B. \& Deng, G. (1994). In Short Chain Fatty Acids (Falk Symposium 73, 1993) [H. J. Binder, J. Cummings and K. H. Soergel, editors]. Lancaster: Kluwer Academic.

Klatsky, A. L., Armstrong, M. A., Freidman, G. D. \& Hiatt, R. A. (1988). The relations of alcoholic beverage use to colon and rectal cancer. American Journal of Epidemiology 128, 1007-1015.

Kleibeuker, J. H., Welberg, J. W. M., Mulder, N. H., Vandermeer, R., Cats, A., Limburg, A. J., Kreumer, W. M. T., Hardonk, M. J. \& De Vries, E. G. E. (1993). Epithelial cell proliferation in the sigmoid colon of patients with adenomatous polyps increases during oral calcium supplementation. British Journal of Cancer 67 , $500-503$.

Klurfeld, D. M. (1990). Insoluble dietary fiber and colon cancer. In Dietary Fiber, pp. $403-416$ [D. Kritchevsky, C. Bonfield \& J. W. Anderson, editors]. New York: Plenum Press.

Knekt, P., Reunanen, A., Takkunene, H., Aromaa, A., Heliovaara, M. \& Hakulinene, T. (1989). Body iron stores and risk of cancer. International Journal of Cancer 56, 379-382.

Kono, S., Imanishi, K., Shinchi, K. \& Yanai, F. (1993). Relationship of diet to small and large adenomas of the sigmoid colon. Japanese Journal of Cancer Research 84, 13-19.

Kruh, J. (1982). Effect of sodium butyrate, a new pharmacological agent, on cells in culture. Molecular and Cellular Biochemistry 42, 65-82.

Kruh, J., Defer, N. \& Tichonicky, L. (1991). Molecular and cellular effects of sodium butyrate. In Report of the 10th Ross Conference on Medical Research, pp. 45-50. Columbus, OH: Ross Laboratories.

Kruh, J., Defer, N. \& Tichonicky, L. (1994). Effects of butyrate on cell proliferation and gene expression. In Physiological and Clinical Aspects of $S C F A$, ch. 18 [J. H. Cummings et al. editors]. Cambridge: Cambridge University Press.

Kubben, F., Engels, L., Arends, J. et al. (1994). The influence of one year calcium supplementation on colorectal epithelial cell proliferation in adenoma patients. In Proceedings of the 10th World Congress of Gastroenterology, Abstract 13.

Kuratko, C. \& Pence, B. C. (1995). Dietary lipid and iron modify normal colonic mucosa without affecting phospholipase A2 activity. Cancer Letters 95, 181-187.

Kuratsune, M., Honda, T., Englyst, H. N. \& Cummings, J. H. (1986). Dietary fiber in the Japanese diet as investigated in connection with colon cancer risk. Japanese Journal of Cancer Research 77, 736-738.

Laird, P. W., Jackson-Grusby, L., Fazeli, A., Dickinson, S. L., Jung, W. E., Li, E., Weinberg, R. A. \& Jaenisch, R. (1995). Suppression of intestinal neoplasia by DNA hypomethylation. Cell 81, 197-205.

Lashner, B. A. (1993). Red blood cell folate is associated with the development of dysplasia and cancer in ulcerative colitis. Journal of Cancer Research and Clinical Oncology 119, 549-554.

Lashner, B. A., Heidenreich, P. A., Su, G. L., Kane, S. V. \& Hanauer, S. B. (1989). Effect of folate supplementation on the incidence of dysplasia and cancer in chronic ulcerative colitis. Gastroenterology 97 , 255-259.

Layton, D. W., Bogen, K. T., Knize, M. G., Hatch, F. T., Johnson, V. M. \& Felton, J. S. (1995). Cancer risk of heterocyclic amines in cooked foods. Carcinogenesis 16, 39-62.

Leaf, A. \& Weber, P. C. (1988). Cardiovascular effects of n-3 fatty acids. New England Journal of Medicine 318, 549-557.

Leaf, C. D., Wishnok, J. S. \& Tannenbaum, S. R. (1989). Mechanisms of endogenous nitrosation. Cancer Surveys 8, 323-334.

Ling, W. H. \& Hänninen, O. (1992). Shifting from a conventional diet to an uncooked vegan diet reversibly alters fecal hydrolytic activities in humans. Journal of Nutrition 122, 924-930. 
Little, I., Logan, R., Hawtin, P., Hardcastle, J. D. \& Turner, I. D. (1991). Colorectal adenomas and dietary fat, protein, fibre and calcium. Gastroenterology $\mathbf{1 0 0}$, A380.

Lotfi, A. M., Spencer, R. J., Ilstrup, D. M. \& Melton, L. J, (1986). Colorectal polyps and risk of subsequent carcinoma. Mayo Clinic Proceedings 61, 337-343.

Longnecker, M. P., Moreno, J. M. M., Knekt, P., Nomura, A. M. Y., Schober, S. E., Stahelin, H. B., Wald, N. J., Gey, K. F. \& Willett, W. C. (1992). Serum $\alpha$-tocopherol concentration in relation to subsequent colorectal cancer: pooled data from five cohorts. Journal of the National Cancer Institute 84, 430-435.

Longnecker, M. P., Orza, M. J., Adams, M. E. et al. (1990). A meta analysis of alcoholic beverage consumption in relation to colorectal cancer. Cancer Causes and Control 1, 59-68.

Loub, W. D., Wattenberg, L. W. \& Davis, D. W. (1975). Aryl hydrocarbon hydroxylase induction in rat tissues by naturally occurring indoles of cruciferous plants. Journal of the National Cancer Institute 54, $985-988$.

Lupton, J. R. \& Marchant, L. J. (1989). Independent effects of fiber and protein on colonic luminal ammonia concentration. Journal of Nutrition 19, 235-241.

McBurney, M. I., Horvath, P. J., Jeraci, J. L. \& Van Soest, P. J. (1985). Effect of in vitro fermentation using human faecal inoculum on the water holding capacity of dietary fibre. British Journal of Nutrition 53, 17-24.

McConnell, J. B., Murison, J. \& Stewart, W. K. (1979). The role of the colon in the pathogenesis of hyperchloraemic acidosis in ureterosigmoid anastomosis. Clinical Science 57, 305-312.

Macfarlane, G. T. \& Cummings, J. H. (1991). The colonic flora, fermentation, and large bowel digestive function. In The Large Intestine: Physiology, Pathophysiology and Disease, pp. 51-92 [S. F. Phillips, J. H. Pemberton and R. G. Shorter, editors]. New York: Raven Press.

Macfarlane, G. T., Cummings, J. H. \& Allison, C. (1986). Protein degradation by human intestinal bacteria. Journal of General Microbiology 132, 1647-1656.

McKeown-Eyssen, G. (1994). Review: triglycerides, glucose and colorectal cancer. Cancer Epidemiology, Biomarkers and Prevention 3, 687-695.

McKeown-Eyssen, G. \& Bright-See, E. (1985). Dietary factors in colon cancer: international relationships. An update. Nutrition and Cancer 7, 251-253.

McKeown-Eyssen, G., Holloway, C., Jazmaji, V., Bright-see, E., Dion, P. \& Bruce, W. R. (1988). A randomised trial of vitamins $C$ and $E$ in the prevention of recurrence of colorectal polyps. Cancer Research $\mathbf{4 8 , 4 7 0 1 - 4 7 0 5 .}$

MacLennan, R., Macrae, F., Bain, C., Battistutta, D., Chapuis, P., Gratten, H., Lambert, J., Newland, R. C., Ngu, M., Russell, A., Ward, M. \& Wahlqvist, M. L. (1995). Randomized trial of intake of fat, fiber, and beta carotene to prevent colorectal adenomas. Journal of the National Cancer Institute 87, 1760-1766.

MacLennan, R., Ward, M., MacRae, F., Wahlqvist, M., Goulston, K., Ngu, M., Battistuta, D. \& Gratten, H. (1991). Effect of fat, fiber and beta carotene on occurrence of colorectal adenomas after 24 months. Gastroenterology 100, A382.

McMichael, A. J., McCall, M. G., Hartshorne, J. M. \& Woodings, T. L. (1980). Patterns of gastrointestinal cancer in European migrants to Australia - the role of dietary change. International Journal of Cancer 25, 431-437.

McMichael, A. J., Potter, J. D. \& Hetzel, B. S. (1979). Time trends in colorectal cancer mortality in relation to food and alcohol consumption: United States, United Kingdom, Australia and New Zealand. International Journal of Epidemiology 8, 295-303.

MacQuart-Moulin, G., Riboli, E., Cornée, J., Kaaks, R. \& Berthezène, P. (1987). Colorectal polyps and diet: a case-control study in Marseilles. International Journal of Cancer 40, 179-188.

Mallett, A. K., Rowland, I. R. \& Bearne, C. A. (1986). Influence of wheat bran on some reductive and hydrolytic activities of the rat cecal flora. Nutrition and Cancer 8, 125-131.

Mallett, A. K., Rowland, I. R., Bearne, C. A., Flynn, J. C., Fehilly, B. J., Udeen, S. \& Farthing, M. (1988a) Effects of dietary supplements of apple pectin, wheat bran or fat on the enzyme activity of the human fecal flora. Microbiology and Ecology of Health and Disease 1, 23-29.

Mallett, A. K., Walters, D. G. \& Rowland, I. R. (1988b). Protein-related differences in the excretion of nitrosoproline and nitrate by the rat-possible modification of de novo nitrate synthesis. Food and Chemical Toxicology 26, 831-835.

Margetts, B. (1994). Diet and Cancer: Review of the Epidemiological Literature. London: The Nutrition Society.

Margison, G. P. \& O'Connor, P. J. (1990). Biological consequences of reactions with NDA: role of specific lesions. In Handbook of Experimental Pharmacology, vol. 94, pp. 547-571 [C. S. Cooper and P. L. Grover, editors]. Berlin: Springer.

Marnett, L. J. (1992). Aspirin and the potential role of prostaglandins in colon cancer. Cancer Research 52 , $5575-5589$.

Midvedt, T. \& Norman, A. M. (1968). Parameters in 7- $\alpha$ dehydroxylation of bile acids by anaerobic bacteria. Acta Pathologica et Microbiologica Scandinavica 72, 313-329.

Minowa, M., Bingham, S. \& Cummings, J. H. (1983). Dietary fibre intake in Japan. Human Nutrition: Applied Nutrition 37A, 113-119.

Morgan, J. W., Frazer, G. F., Phillips, R. L. \& Andress, M. H. (1988). Dietary factors and colon cancer incidence among Seventh-Day Adventists. American Journal of Epidemiology 128, 918(A).

Morotomi, M., Giullem, J. G., Logerfo, P. \& Weinstein, I. B. (1990). Production of diacylglycerol, an activator of protein kinase-C, by human intestinal microflora. Cancer Research 50, 3595-3599. 
Muir, C., Waterhouse, J., Mack, T., Powell, J. \& Whelan, S. (editors) (1987). Cancer Incidence in Five Continents, vol. 5. Lyon: International Agency for Research on Cancer.

Mukhtar, H, Wang, Z. Y., Katiyar, S. \& Agarwal, R. (1992). Tea components: antimutagenic and anticarcinogenic effects. Preventive Medicine 21, 351-361.

Nair, P. P., Shami, S., Sainz, E., Menon, M., Jerabek, L. B., Jones, D. Y., Judd, J. T., Campbell, W. S., Schiffman, M. H., Taylor, P. R., Schatzkin, A., Guidry, C. \& Brown, C. C. (1990). Influence of dietary fat on fecal mutagenicity in premenopausal women. International Journal of Cancer 46, 374-377.

Narisawa, T. \& Fukaura, Y. (1993). A very low dose of green tea polyphenols in drinking water prevents $N$-methyl- $N$-nitrosourea-induced colon carcinogenesis in F344 rats. Japanese Journal of Cancer Research 84, 1007-1009.

Narisawa, T., Napoleon, E., Magadia, J. H., Weisburger, J. H. \& Wynder, E. L. (1974). Promoting effect of bile acids on colon carcinogenesis after intrarectal instillation of $N$-methyl- $N^{\prime}$-nitro- $N$-nitrosoguanidine in rats. Journal of the National Cancer Institute 53, 1093-1095.

Nelson, R. L., Davis, F. G., Sutter, E., Sobin, L. H., Kikendall, J. W. \& Bowen, P. (1994). Body iron stores and risk of colonic neoplasia. Journal of the National Cancer Institute 86, 455-460.

Nelson, R. L., Yoo, S. J., Tanure, J. C., Adrianopoulos, G. \& Misumi, A. (1989). The effect of iron on experimental colorectal carcinogenesis. Anticancer Research 9, 1477-1482.

Neugut, A. I., Grabowski, G. C., Lee, W. C., Murray, T., Nieves, J. W., Forde, K. A., Treat, M. R., Waye, J. D. \& Fenogliopreiser, C. (1993). Dietary risk factors for the incidence and recurrence of colorectal adenomatous polyps. A case-control study. Annals of Internal Medicine 118, 91-95.

Newmark, H. L., Wargovich, M. J. \& Bruce, W. R. (1984). Colon cancer and dietary fat, phosphate, and calcium: a hypothesis. Journal of the National Cancer Institute 72, 1323-1325.

Nijhoff, W. A., Mulder, T. P., Verhagen, H., van Poppel, G. \& Peters, W. H. M. (1995). Effects of consumption of brussels sprouts on plasma and urinary GST in humans. Carcinogenesis 16, 955-957.

Nishizuka, Y. (1986). Studies and perspectives of protein kinase C. Science 233, 305-312.

Noordhoek, J. \& van Bladeren, P. J. (1991). Nutrition and extrahepatic metabolism. In Nutrition, Toxicity and Cancer, pp. 93-112 [I. R. Rowland, editor]. Boca Raton, FL: CRC Press.

O'Neill, I. K., Loktionov, A., Manson, M. M., Ball, H., Bandeletova, T. \& Bingham, S. A. (1996). Effects of vegetables and teas on the colorectal epithelium and metabolic organs that alter its risk for cancer. Proceedings of the American Association for Cancer Research (in press).

O'Neill, I., Ohgaki, H., Ellul, A. \& Turesky, R. J. (1992). Entrapment by magnetic microcapsules of the protein pryolysates IQ, PhIP and Glu-P-1, and alteration of IQ metabolite exposure within the rat gastrointestinal tract by risk-modulating components of the human diet. Carcinogenesis 13, 2353-2359.

Paganelli, G. M., Biasco, G., Brandi, G., Santucci, R., Gizzi, G., Villani, V., Cianci, M., Miglioli, M. \& Barbara, L. (1992). Effect of vitamins A, C, and E supplementation on rectal cell proliferation in patients with colorectal adenomas. Journal of the National Cancer Institute 84, 47-51.

Palmer, R. M. J., Ferrige, A. G. \& Moncada, S. (1987). Nitric oxide release accounts for the biological activity of endothelium-derived relaxing factor. Nature 327, 524-526.

Parkin, D. M., Muir, C. S., Whelan, S. L., Gao, Y. T., Ferlay, J. \& Powell, (1992). Cancer Incidence in Five Continents, vol. 6 (IARC Scientific Publication no. 120). Lyon: International Association for Research on Cancer.

Peltomäki, P., Aaltonen, L. A., Sistonen, P., Pylkkänen, L., Mecklin, J.-P., Järvinen, H., Green, J. S., Jaso, J. R., Weber, J. L., Leach, F. S., Petersen, G. M., Hamilton, S. R., de la Chapelle, A. \& Vogelstein, B. (1993). Genetic mapping of a locus predisposing to human colorectal cancer. Science 260, 810-812.

Pence, B. C., Buddingh, F. \& Yang, S. P. (1986). Multiple dietary factors in the enhancement of dimethylhydrazine carcinogenesis: main effect of indole-3-carbinol. Journal of the National Cancer Institute 77, 269-276.

Pence, B. P., Butler, M. J., Dunn, D. M., Miller, M. F., Zhao, C. \& Landers, M. (1995). Non promoting effects of lean beef in the rat colon carcinogenesis model. Carcinogenesis 16, 1157-1160.

Peto, R., Gray, R., Brantom, P. \& Grasso, P. (1984). Nitrosamine carcinogenicity in 5120 rodents. In Evaluation of Carcinogenic Risk of Chemicals to Humans (IARC Publication no. 57), pp. 627-666 [O'Neill et al. editors]. Lyon: International Association for Research on Cancer.

Phillips, J., Muir, J. G., Birkett, A., Lu, Z. X., Jones, G. P., O'Dea, K. \& Young, G. P. (1995). Effect of resistant starch on fecal bulk and fermentation-dependent events in humans. American Journal of Clinical Nutrition 62 , $121-130$.

Phillips, R. L. \& Snowdon, D. A. (1985). Dietary relationships with fatal colorectal cancer among Seventh-Day Adventists. Journal of the National Cancer Institute 74, 307-317.

Phillips, R. L. \& Snowdon, D. A. (1993). Association of meat and coffee use with cancers of the large bowel. Cancer Research 43 (Suppl.) 2403s-2408s.

Pilch, S. (editor) (1987). Physiological Effects and Health Consequences of Dietary Fiber. Bethesda, MD: FASEB.

Porter, J. W. G. \& Rolls, B. A. (1971). Some aspects of the digestion of proteins. Proceedings of the Nutrition Society 30, 17-25.

Potter, J. D., Slattery, M. L., Bostick, R. M. \& Gapstur, S. M. (1994). Colon cancer, a review of the epidemiology. Epidemiologic Reviews 15, 489-545. 
Powles, J. \& Williams, D. R. R. (1984). Trends in bowel cancer in selected countries in relation to wartime changes in flour milling. Nutrition and Cancer 6, 40-48.

Preussman, R. (1984). Occurrence and exposure to $N$-nitroso compounds. In Evaluation of Carcinogenic Risk of Chemicals to Humans (IARC Publication no. 57), pp. 3-15 [O'Neill et al. editors]. Lyon: International Association for Research on Cancer.

Quian, G., Ross, K., Yu, M., Yuan, J., Gao, Y., Henderson, B., Wogan, G. \& Groopman, J. (1994). A followup study of urinary markers of aflatoxin exposure and liver cancer risk in Shanghai, People's Republic of China. Cancer Epidemiology, Biomarkers and Prevention 3, 3-10.

Rafter, J. J., Eng, V. W. S., Furrer, R., Medline, A. \& Bruce, W. R. (1986). Effects of calcium and $\mathrm{pH}$ on the mucosal damage produced by deoxycholic acid in the rat colon. Gut 27, 1320-1329.

Reddy, B. S., Burill, C. \& Rigotty, J. (1991). Effects of diets high in $\omega 3$ and $\omega 6$ fatty acids on initiation and postinitiation stages of colon carcinogenesis. Cancer Research 51, 487-491.

Reddy, B. S., Narasawa, T. \& Weisburger, J. (1976). Effect of a diet with high levels of protein and fat on colon cacinogenesis in F344 rats treated with 1,2dimethylhydrazine. Journal of the National Cancer Institute 57, $567-569$.

Reddy, B. S., Nayini, J., Tokumo, K., Rigotty, J., Zang, E. \& Kelloff, G. (1990). Chemoprevention of colon carcinogenesis by concurrent administration of piroxicam, a nonsteroidal antiinflammatory drug with $\mathrm{D}, \mathrm{L}-\alpha-$ diffuoromethylornithine, an ornithine decarboxylase inhibitor, in diet. Cancer Research 50, 2562-2568.

Reddy, B., Rao, C. V. \& Rivenson, A. (1993). Aspirin inhibits cancer of the colon. Gastroenterology 104, A443.

Reddy, B. S., Sharma, C., Simi, B., Engle, A., Laakso, K., Puska, P. \& Korpela, R. (1987). Metabolic epidemiology of colon cancer: effect of dietary fiber on fecal mutagens and bile acids in healthy subjects. Cancer Research 47, 644-648.

Reddy, B. S., Simi, B. \& Engle, A. (1994). Effect of types of fibre on colonic DAG in women. Gastroenterology 106, 883-889.

Reddy, B. \& Sugie, S. (1988). Effect of different levels of $\omega 3$ and $\omega 6$ fatty acids on azoxymethane induced colon carcinogenesis in F344 rats. Cancer Research 48, 6642-6647.

Reddy, B. S., Weisburger, J. H. \& Wynder, E. L. (1974). Fecal bacterial $\beta$-glucuronidase: control by diet. Science $183,416-417$.

Rodriguez, J. W., Kirlin, W. G., Ferguson, R. J., Doll, M. A., Gray, K., Rustan, T. D., Lee, M. E., Kemp, K., Urso, P. \& Hein, D. W. (1993). Human acetylator genotype: relationship to colorectal cancer incidence and arylamine $\mathrm{N}$-acetyltransferase expression in colon cytosol. Archives of Toxicology 67, 445 452.

Roediger, W. E. W. (1980). Role of anaerobic bacteria in the metabolic welfare of the colonic mucosa in man. Gut 21, 793-798.

Roediger, W. E. W., Duncan, A., Kapaniris, O. \& Millard, S. (1993). Reducing sulfur compounds of the colon impair colonocyte nutrition. Implications for ulcerative colitis. Gastroenterology 104, 802-809.

Roger, C. R. (1988). The nutritional incidence of flavonoids: some physiological and metabolic considerations. Experientia 44, 725-804.

Rogers, A. E., Zeisel, S. H. \& Groopman, J. (1993). Diet and carcinogenesis. Carcinogenesis 14, $2205-2217$.

Rowland, I. R. (1991). Nutrition and gut flora metabolism. In Nutrition, Toxicity and Cancer, pp. 113-196 [I. R. Rowland, editor]. Boca Raton, FL: CRC Press.

Rowland, I. R., Granli, T., Bockman, O. C., Key, P. E. \& Massey, R. C. (1991). Endogenous $N$-nitrosation in man assessed by measurement of apparent total $N$-nitroso compounds in feces. Carcinogenesis 12, $1395-1401$.

Rowland, I. R. \& Mallett, A. K. (1990). The influence of dietary fibre on the microbial enzyme activity in the gut. In Dietary Fibre, Chemistry, Physiology and Health Effects, pp. 195-206 [D. Kritchevsky, C. Bonfield and J. W. Anderson, editors]. New York: Plenum Press.

Rowland, I. R., Mallett, A. K., Bearne, C. A. \& Farthing, M. J. G. (1986). Enzyme activities of the hind gut microflora of laboratory animals and man. Xenobiotica 16, 519-523.

Rowland, I. R. \& Tanaka, R. (1993). The effects of transgalactosylated oligosaccharides on gut flora metabolism in rats associated with a human faecal microflora. Journal of Applied Bacteriology 74, 667-674.

Rumney, C. J., Rowland, I. R., Coutts, T. M., Randerath, K., Reddy, R., Shah, A. B., Ellul, A. \& O'Neill, I. K. (1993). Effects of risk associated human dietary macrocomponents on processes related to carcinogenesis in human-flora-associated (HFA) rats. Carcinogenesis 14, 79-84.

Sandler, R. S., Lyles, C. M., Peipins, L. A., McAuliffe, C. A., Woosley, J. T. \& Kupper, L. L. (1993). Diet and risk of colorectal adenomas - macronutrients, cholesterol and fiber. Journal of the National Cancer Institute $\mathbf{8 5}$, 884-891.

Scheppach, W., Burghart, W., Bartram, P. et al. (1990). Addition of dietary fibre to liquid formula diets. Journal of Parenteral and Enteral Nutrition 14, 204-209.

Scheppach, W., Fabian, C., Sachs, M.\& Kasper, H. (1988). The effect of starch malabsorption on fecal short chain fatty acid excretion in man. Scandinavian Journal of Gastroenterology 23, 755-759.

Scheppach, W. B., Richter, A., Liepald, H. et al. (1992). Effect of short chain fatty acids on the human colonic mucosa in vitro. Journal of Parenteral and Enteral Nutrition 16, 43-48.

Schiffman, M. H. (1987). Diet and faecal genotoxicity. Cancer Surveys 6, 653-672.

Schiffman, M. H., Van Tassell, R. L., Robinson, A., Smith, L. et al. (1989). Case control study of colorectal cancer and fecapentaene excretion. Cancer Research 49, 1322-1326. 
Schofield, P. F. \& Jones, D. J. (1992), Colorectal neoplasia I: Benign colonic tumours. British Medical Journal 304, 1498-1500.

Segal, I., Walker, A. R. P., Lord, S. \& Cummings, J. H. (1988). Breath methane and large bowel cancer risk in contrasting African populations. Gut 29, 608-613.

Setchell, K. D. R. \& Adlercreutz, H. (1988). Mammalian lignans and phytoestrogens. In Role of the Gut Flora in Toxicity and Cancer, pp. 315-345 [I. R. Rowland, editor]. New York: Academic Press.

Setchell, K. D. R., Street, J. M. \& Sjovall, J. (1987). Fecal bile acids. In The Bile Acids, pp. 441-570 [K. D. R. Setchell, D. Kritchevsky \& P. P. Nair, editors]. New York: Plenum Press.

Severson, R. K., Nomura, A. M. Y., Grove, J. S. \& Stemmermann, G. N. (1989). A prospective analysis of physical activity and cancer. American Journal of Epidemiology 130, 522-529.

Shibata, A., Paganini-Hill, A., Ross, R. K., Henderson, R. \& Henderson, B. E. (1992). Intake of vegetables, fruits, $\beta$-carotene, vitamin $\mathrm{C}$ and vitamin supplements and cancer incidence among the elderly: a prospective study. British Journal of Cancer 66, 673-679.

Shuker, D. E. G. (1989). Detection of adducts arising from human exposure to $N$-nitroso compounds. Cancer Surveys 8, 475-487.

Silvester, K. R., Bingham, S., Loktionov, A., Cummings, J. \& O'Neill, I. (1995). Effect of dietary meat on endogenous $N$-nitroso compound formation and frequency of k-ras mutants in faecal isolated colonic cells. Proceedings of the Conference on Molecular Aspects of Carcinogenesis, York (in press).

Silvester, K. R. \& Cummings, J. H. (1995). Does digestibility of meat protein help explain large bowel cancer risk? Nutrition and Cancer 24, 279-288.

Sinkeldam, E. J., Kuper, C. F., Bosland, M. C., Hollanders, V. M. H. \& Vedder, D. M. (1990). Interactive effects of dietary wheat bran and lard on $N$-methyl- $N$-nitro- $N$-nitrosoguanidine-induced colon carcinogenesis in rats. Cancer Research 50, 1092-1096.

Slattery, M. L., Sorenson, A. W., Mahoney, A. W., French, T. K., Kritchevsky, D. \& Street, J. C. (1988). Diet and colon cancer: assessment of risk by fiber type and food source. Journal of the National Cancer Institute $\mathbf{8 0}$, $1474-1480$.

Slob, I. C. M., Lambregts, L. M. C., Schuit, A. J. \& Kok, F. J. (1993). Calcium intake and 28-year gastrointestinal cancer mortality in Dutch civil servants. International Journal of Cancer 54, 20-25.

Smith, P. J. (1986). n-Butyrate alters chromatin accessibility to DNA repair enzymes. Carcinogenesis 7, $423-429$.

Solomon, E., Voss, R., Hall, V., Bodmer, W. F., Jaso, J. R., Jeffreys, A. J., Lucibello, F. C., Patel, I. \& Rider, S. H. (1987). Chromosome 5 allele loss in human colorectal carcinomas. Nature 328, 616-619.

Sonnenberg, A. \& Muller, A. (1993). Constipation and cathartics as risk factors in colorectal cancer. Pharmacology 47, 224-233.

Sparnins, V. L., Barany, G. \& Wattenberg, L. W. (1988). Effects of organosulphur compounds from garlic and onions on benzo[a]pyrene induced neoplasia and glutathione S-transferase activity in the mouse. Carcinogenesis 9, $131-134$.

Stahelin, H. B., Gey, K. F., Eichholzer, M., Ludin, E., Bernasconi, F., Thurneysen, J. \& Brubacher, G. (1991). Plasma antioxidant vitamins and subsequent cancer mortality in the 12-year follow-up of the prospective Basel study. American Journal of Epidemiology 133, 766-775.

Steinbach, G., Kumar, S. P., Reddy, B. S., Lipkin, M. \& Holt, P. R. (1993). Effects of caloric restriction and dietary fat on epithelial cell proliferation in rat colon. Cancer Research 53, 2745-2749.

Steinmetz, K. A., Kushi, L. H., Bostick, R. M., Folsom, A. R. \& Potter, J. D. (1994). Vegetables, fruit and colon cancer in the Iowa Women's health study. American Journal of Epidemiology 139, 1-15.

Stemmermann, G. N., Heilbrun, L. K. \& Nomura, A. M. Y. (1988). Association of diet and other factors with adenomatous polyps of the large bowel: a prospective autopsy study. American Journal of Clinical Nutrition 47 , 312-317.

Stemmermann, G. N., Nomura, A. M. Y. \& Heilbrun, L. K. (1984). Dietary fat and the risk of colorectal cancer. Cancer Research 44, 4633-4637.

Stevens, R. G., Graubard, B. I., Micozzi, M. S., Neriishi, K. \& Blumberg, B. S. (1994). Moderate elevation of body iron level and increased risk of cancer occurrence and death. International Journal of Cancer 56, 364-369.

Strange, R. C., Matharoo, B., Faulder, G. C., Jones, P., Cotton, W., Elder, J. B. \& Deakin, M. (1991). The human glutathione S-transferases: a case-control study of the incidence of the GST1-O phenotype in patients with adenocarcinoma. Carcinogenesis 12, 25-28.

Stuehr, D. J. \& Marletta, M. A. (1985). Mammalian nitrate biosynthesis: mouse macrophages produce nitrite and nitrate in response to Escherichia coli lipopolysaccharide. Proceedings of the National Academy of Sciences, USA 82, 7738-7742.

Sugimura, T. (1986). Past, present, and future of mutagens in cooked foods. Environmental Health Perspectives 67, 5-10.

Suzuki, K. \& Mitsuoka, T. (1984). N-nitrosamine formation by intestinal bacteria. In Evaluation of Carcinogenic Risk of Chemicals to Humans (IARC Publication no. 57) pp. 275-281 [O'Neill et al editors]. Lyon: International Association for Research on Cancer.

Takahashi, S., Hakoi, K., Yada, H., Hirose, M., Ito, N. \& Fukushima, S. (1992). Enhancing effects of diallyl sulphide on hepatocarcinogenesis and inhibitory actions of the related diallyl disulphide on colon and renal carcinogenesis in rats. Carcinogenesis 13, 1513-1518. 
Takahashi, M., Minamoto, T., Yamashita, N., Yazawa, K., Sugimura, T. \& Esumi, H. (1993). Reduction in formation and growth of 1,2-dimethylhydrazine aberrant crypt foci in rat colon by docosahexaenoic acid. Cancer Research 53, 2786-2789.

Takayama, S., Nakatsuru, Y., Masuda, M., Ohgaki, H., Sato, S. \& Sugimura, T. (1984). Demonstration of the carcinogenicity in F344 rats of 2-amino-3-methylimidazo[4,5-f]quinoline from broiled sardine, fried beef and beef extract. Gann 75, 467-470.

Talalay, P., Prochaska, H. J. \& Spencer, S. R. (1991). Regulation of enzymes that detoxify the electrophilic forms of chemical carcinogens. In Xenobiotics and Cancer, pp. 177-187 [L. Ernster et al., editors]. London: Taylor \& Francis.

Tank, E. S., Krausch, D. N. \& Lapides, J. (1973). Adenocarcinoma of the colon associated with ureterosigmoidoscopy. Diseases of the Colon and Rectum 16, 300-304.

Thind, I. S. (1986). Diet and cancer: an international study. International Journal of Epidemiology 15, 160-163.

Thun, M. J., Calle, E. E., Namboodiri, M. M., Flanders, W. D., Coates, R. J., Byers, T., Boffetta, P., Garfinkel, L. \& Heath, C. W. (1992). Risk factors for fatal colon cancer in a large prospective study. Journal of the National Cancer Institute 84, 1491-1500.

Tomatis, L., Aitio, A., Day, N. E., Heseltine, E., Kaldor, J., Miller, A. B., Parkin, D. M. \& Riboli, E. (editors) (1990). Cancer: Causes, Occurrence and Control (IARC Scientific Publication no. 100). Lyon: International Agency for Research on Cancer.

Topping, D. C. \& Visek, W. J. (1976). Nitrogen intake and tumorigenesis in rats injected with 1,2dimethylhydrazine. Journal of Nutrition 106, 1583-1590.

Toscani, A., Soprano, D. R. \& Soprano, K. J. (1988). Molecular analysis of sodium butyrate induced growth arrest. Oncogene Research 3, 223.

Trock, B., Lanza, E. \& Greenwald, P. (1990). Dietary fiber, vegetables and colon cancer : critical review and metaanalysis of the epidemiologic evidence. Journal of the National Cancer Institute 82, 650-661.

Tsujii, M., Kawano, S., Tsuji, S., Ito, T., Nagano, K., Sasaki, Y., Hayashi, N., Fusamoto, H. \& Kamada, T. (1993). Cell kinetics of mucosal atrophy in rat stomach induced by long-term administration of ammonia. Gastroenterology 104, 796-801.

Tsujii, M., Kawano, S., Tsuji, S., Nagano, K., Ito, T., Hayashi, N., Fusamoto, H., Kamada, T. \& Tamura, K. (1992). Ammonia - a possible promoter in Helicobacter pylori related gastric carcinogenesis. Cancer Letters $\mathbf{6 5}$, 15-18.

Turesky, R. J., Lang, N. P., Butler, M. A., Teitel, C. H. \& Kadlubar, F. F. (1991). Metabolic activation of carcinogenic heterocyclic aromatic amines by human liver and colon. Carcinogenesis 12, $1839-1845$.

Tuyns, A. F., Kaaks, R. \& Haelterman, M. (1987). Colorectal cancer and the consumption of nutrients: a case control study in Belgium. Nutrition and Cancer 10, 181-196.

Ullah, A. \& Shamsuddin, A. M. (1990). Dose dependent inhibition of large intestinal cancer by inositol hexaphosphate in F344 rats. Carcinogenesis 11, 2219-2222.

Van Munster, I. P., Tangerman, A. \& Nagengast, F. M. (1994). Effect of resistant starch on colonic fermentation, bile acid metabolism, and mucosal proliferation. Digestive Diseases and Sciences 39, 834-842.

Van Tassell, R. L., Piccariello, T., Kingston, D. G. I. \& Wilkins, T. D. (1989). The precursors of fecapentaenes: purification and properties of a novel plasmalogen. Lipids 24, $454 \mathbf{4 5 9}$.

Venitt, S., Bosworth, D. \& Alldrick, A. J. (1986). Pilot study of the effect of diet on the mutagenicity of human faeces. Mutagenesis 1, 353-358.

Verhagen, H., Poulsen, H. E., Loft, S., van Poppel, G., Willems, M. I., \& van Bladeren, P. J. (1995). Reduction of oxidative DNA-damage in humans by Brussels sprouts. Carcinogenesis 16, 969-970.

Visek, W. J. (1978). Diet and cell growth modulation by ammonia. American Journal of Clinical Nutrition 31 (Suppl.), S216-S220.

Vogelstein, B., Fearon, E. R., Hamilton, S. R., Kern, S. E., Preisinger, A. C., Leppert, M., Nakamura, Y., White, R., Smits, A. M. M. \& Bos, J. L. (1988). Genetic alterations during colorectal-tumour development. New England Journal of Medicine 319, 525-532.

Wagner, D. A., Young, V. R. \& Tannenbaum, S. R. (1983). Mammalian nitrate biosynthesis: incorporation of ${ }^{15} \mathrm{NH}_{3}$ into nitrate is enhanced by endotoxin treatment. Proceedings of the National Academy of Sciences, USA 80, 4518-4521.

Wakabayashi, K., Nagao, M., Esumi, H. \& Sugimura, T. (1992). Food-derived mutagens and carcinogens. Cancer Research 52 (Suppl.), 2092-2098s.

Ward, F. W., Coates, M. E. \& Walker, R. (1989). Influence of dietary protein and gut microflora on endogenesis synthesis of nitrate and $N$-nitrosamines in the rat. Food and Chemical Toxicology 27, 445-449.

Ward, J. M., Anjo, T., Ohannesian, L., Keefer, L. K., Devor, D. E., Donovan, P. J., Smith, G. T., Henneman, J. R., Streeter, A. J., Konishi, N., Rehm, S., Reist, E. J., Bradford, W. W. \& Rice, J. M. (1988). Inactivity of fecapentaene-12 as a rodent carcinogen or tumour initiator. Cancer Letters 42, 49-59.

Wargovich, M. J. (1987). Diallyl sulphide, a flavour component of garlic (Allium sativum) inhibits dimethylhydrazine-induced colon cancer. Carcinogenesis 8, 487-489.

Wattenberg, L. W. (1971). Studies of polycyclic hydrocarbon hydroxylases of the intestine possibly related to cancer. Effect of diet on benzpyrene hydroxylase activity. Cancer 28, 99-102.

Wattenberg, L. W. (1985). Chemoprevention of cancer. Cancer Research 45, 1-8. 
Weisburger, J. H. (1993). Heterocyclic amines in foods-possible human carcinogens. Cancer Research 53, $2422-2424$.

Weisburger, J. H., Jones, R. C., Wang, C.-X., Backlund, J. Y. C., Williams, G. M., Kingston, D. G. I., van Tassell, R. L., Keyes, R. F., Wilkins, T. D., de Wit, P. P., van der Steeg, M. \& van der Gen, A. (1990). Carcinogenicity test of fecapentaene-12 in mice and rats. Cancer Letters 49, 89-98.

Weisburger, J. H., Rivenson, A., Reinhardt, J., Aliaga, C., Braley, J., Dolan, L. M., Williams, G. M., Zang, E., Kingston, D. G. I., Bashir, M. et al. (1994). Genotoxicity in rats $7 \mathrm{OH} \mathrm{IQ,} \mathrm{and} \mathrm{intestinal} \mathrm{metabolite} \mathrm{of} \mathrm{IQ.}$ Journal of the National Cancer Institute 86, 25-30.

Weisgerber, U. M., Boeing, H., Owen, R. W., Waldherr, R., Raedsch, R. \& Wahrendorf, J. (1995). Effect of a long term placebo controlled calcium intervention on sigmoidal cell proliferation in patients with sporadic colorectal adenomas. Gut (in press).

Whitehead, N., Reyner, F. \& Lindenbaum, J. (1973). Megaloblastic changes in the cervical epithelium. Journal of the American Medical Association 226, 1421-1424.

Willett, W. C., Stampfer, M. J., Colditz, G. A., Rosner, B. A. \& Speizer, F. E. (1990). Relation of meat, fat, and fiber intake to the risk of colon cancer in a prospective study among women. New England Journal of Medicine 323, $1664-1672$.

Williams, R. T. (1978). Nutrients in drug detoxification mechanisms. In Nutrition in Drug Interrelations, pp. 303-318 [J. Coon and J. H. Hathcock, editors]. New York: Academic Press.

Witter, J. P., Balish, E. \& Gatley, S. J. (1979). Origin of excess urinary nitrate in the rat. Cancer Research 42, 3645-3648.

World Health Organization (1973). Energy and Protein Requirements (Technical Report Series no. 522). Geneva: WHO.

World Health Organization (1990). Diet, Nutrition and the Prevention of Chronic Disease (Technical Report Series no. 797). Geneva: WHO.

Yamane, T., Hagiwara, N., Tateishi, M., Akachi, S., Kim, M., Okuzumi, J., Kitao, Y., Inagake, M., Kuwata, K. \& Takahashi, T. (1991). Inhibition of azoxymethane-induced colon carcinogenesis in rats by green tea polyphenol fraction. Japanese Journal of Cancer Research 82, 1336-1339.

Yang, C. S. \& Wang, Z. Y. (1993). Tea and cancer. Journal of the National Cancer Institute 85, $1038-1049$.

Yang; C. S. \& Yoo, J.-S. H. (1991). Nutrition and hepatic drug metabolism. In Nutrition, Toxicity and Cancer, pp. [I. R. Rowland, editor]. Boca Raton, FL: CRC Press.

Yin, P. Z., Zhao, J. Y., Cheng, S. L., Hara, Y., Zhu, Q. F. \& Liu, Z. G. (1994). Experimental studies of the inhibitory effects of green tea catechin on mice large intestinal cancers induced by 1,2-dimethylhydrazine. Cancer Letters 79, 33-38.

Young, G. P., McIntyre, A., Albert, V., Folino, M., Muir, J. \& Gibson, P. R. (1996). Wheat bran suppresses potato starch-potentiated colorectal tumorigenesis at the aberrant crypt stage in a rat model. Gastroenterology 110, 508-514.

Zaridze, D., Filipchenko, V., Kustov, V., Serdyuk, V.\& Duffy, S. (1993). Diet and colorectal cancer: results of two case-control studies in Russia. European Journal of Cancer 29A, 112-115.

Zarkovic, M., Qin, X. S., Nakatsuru, Y., Oda, H., Nakamura, T., Shamsuddin, A. M. \& Ishikawa, T. (1993). Tumour promotion by fecapentaene-12 in a rat colon carcinogenesis model. Carcinogenesis 14, 1261-1264.

Zhang, Y., Talalay, P., Cho, C.-G. \& Posner, G. H. (1992). A major inducer of anticarcinogenic protective enzymes from broccoli : isolation and elucidation of structure. Proceedings of the National Academy of Sciences, USA 89, 2399-2403.

Zimmerman, J. (1993). Does dietary calcium supplementation reduce the risk of cancer? Nutrition Reviews $\mathbf{5 1}$, 109-112. 